Navigation Systems Research Program

\title{
Modeling Vessel-Generated Currents and Bed Shear Stresses
}

E. Allen Hammack, David S. Smith, and Richard L. Stockstill 


\title{
Modeling Vessel-Generated Currents and Bed Shear Stresses
}

\author{
E. Allen Hammack, David S. Smith, and Richard L. Stockstill \\ Coastal and Hydraulics Laboratory \\ U.S. Army Engineer Research and Development Center \\ 3909 Halls Ferry Road \\ Vicksburg, MS 39180-6199
}

Final report

Approved for public release; distribution is unlimited.

\footnotetext{
Prepared for Headquarters, U.S. Army Corps of Engineers

Washington, DC 20314-1000
} 


\begin{abstract}
Adaptive Hydraulics (ADH) is a computational fluid dynamics package that solves the Navier-Stokes equations and shallow-water (depth-averaged Navier-Stokes) equations on two- and three-dimensional computational meshes for overland flow, sediment transport, and groundwater problems. The capability to model the hydrodynamic effects of vessels moving through a two-dimensional flow field has been added to $\mathrm{ADH}$. Using empirical relations developed by Maynord (2000), the bed shear stresses induced by a barge bow and towboat propeller may also be calculated, which, in turn, can be used to predict sediment transport. Guidelines have been developed for sufficient mesh refinement near the vessel and appropriate values for the mesh adaption parameters in ADH. To demonstrate the new modeling capability, this report describes in detail a study of the effects of a vessel sailing through a stretch of the Illinois Waterway near Kampsville, IL. The vessel-induced shear stresses are also reported for the Kampsville study.
\end{abstract}

DISCLAIMER: The contents of this report are not to be used for advertising, publication, or promotional purposes. Citation of trade names does not constitute an official endorsement or approval of the use of such commercial products. All product names and trademarks cited are the property of their respective owners. The findings of this report are not to be construed as an official Department of the Army position unless so designated by other authorized documents. 


\section{Contents}

Figures and Tables.............................................................................................................................

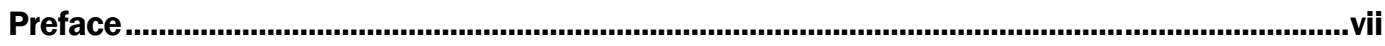

Unit Conversion Factors...........................................................................................................................viii

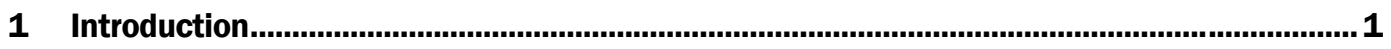

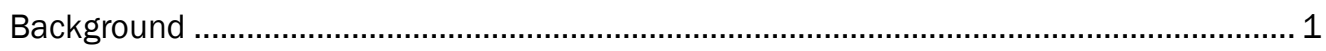

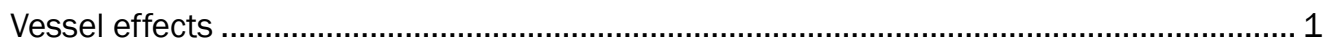

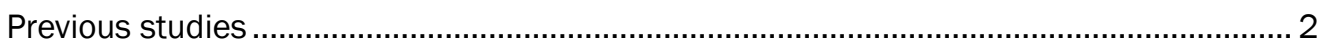

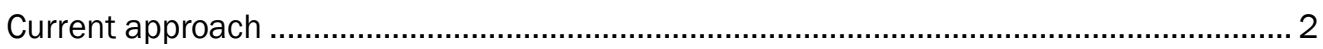

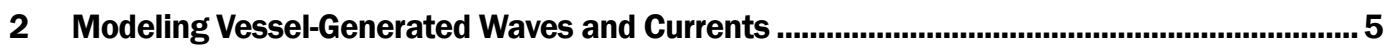

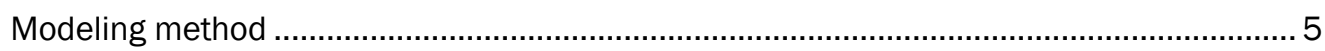

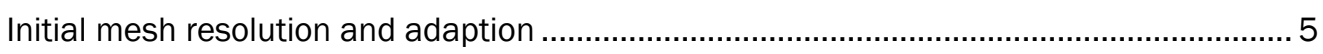

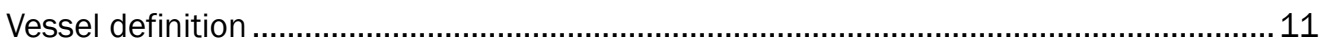

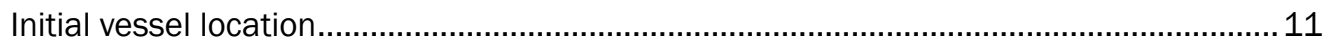

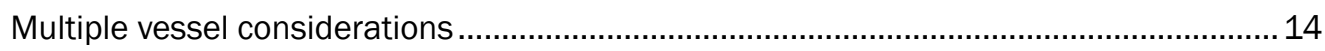

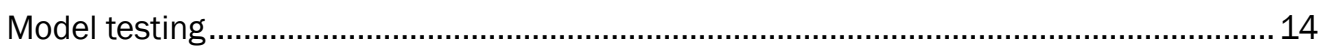

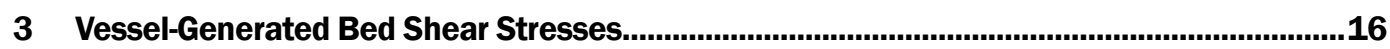

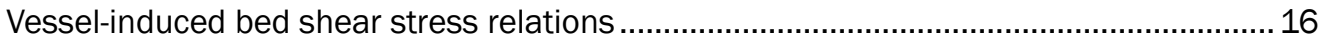

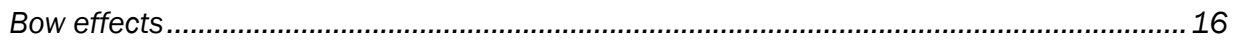

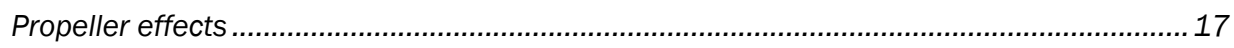

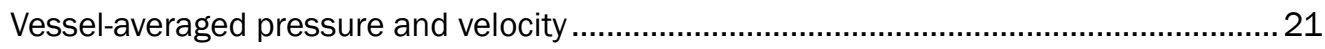

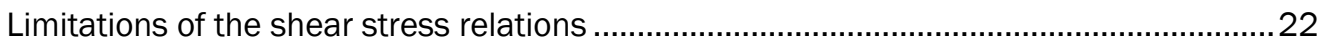

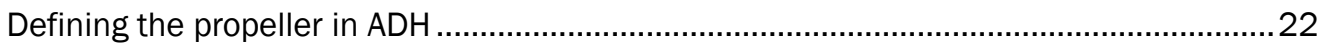

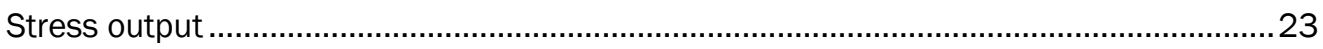

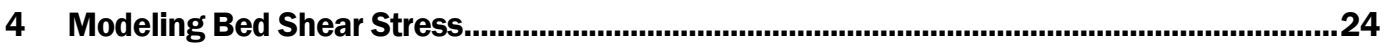

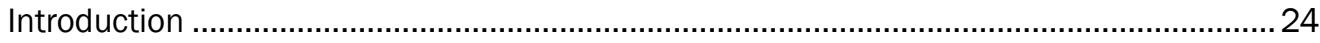

Model setup

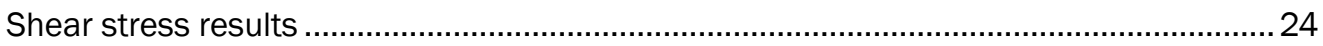

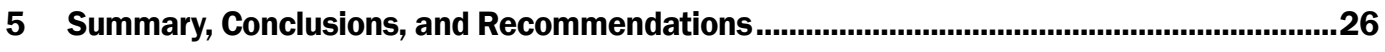

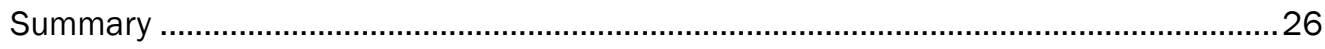

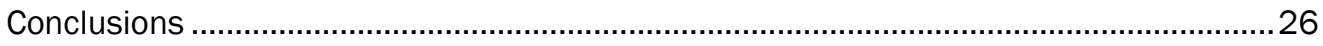

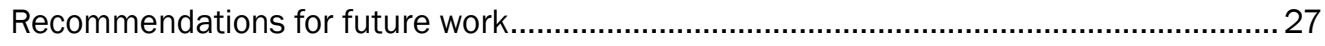

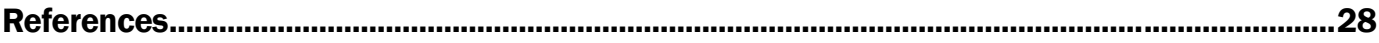

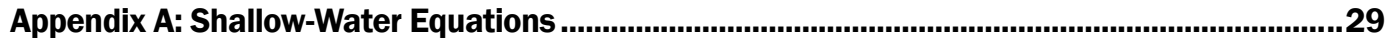

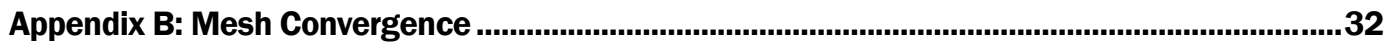




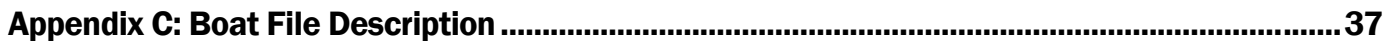

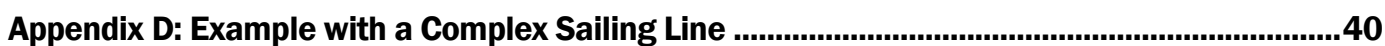

Appendix E: ADH and Field Data Comparison ...........................................................................42

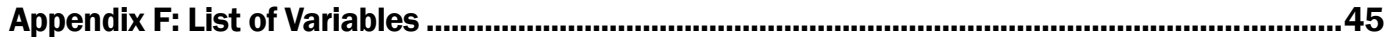

Report Documentation Page 


\section{Figures and Tables}

\section{Figures}

Figure 1. Recommended resolution for the initial mesh.................................................................... 7

Figure 2. Time step selection for vessel movement. .......................................................................... 8

Figure 3. Mesh adaption around the vessel.............................................................................. 10

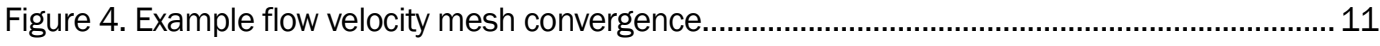

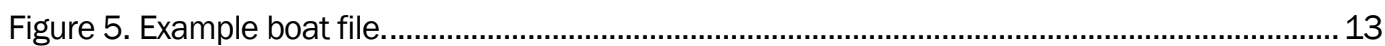

Figure 6. Channel cross-section showing gauge locations relative to the vessel. ............................ 14

Figure 7. Velocity comparison of ADH results and field data. ....................................................... 15

Figure 8. Schematic of propeller terms........................................................................................... 18

Figure 9. Distribution of points used to calculate the vessel pressure head. .................................. 21

Figure 10. Location of ambient velocity calculation point relative to the vessel.............................. 22

Figure 11. Longitudinal shear stress plot in the vessel vicinity along the sailing line. ......................25

Figure 12. Shear stress contours and their location relative to the vessel. ......................................25

Figure B1. Mesh refinement results, longitudinal component of velocity at Gauge 040. ................32

Figure B2. Mesh refinement results, transverse component of velocity at Gauge 040...................32

Figure B3. Mesh refinement results, longitudinal component of velocity at Gauge 071..................33

Figure B4. Mesh refinement results, transverse component of velocity at Gauge 071...................33

Figure B5. Mesh refinement results, longitudinal component of velocity at Gauge 332. ................34

Figure B6. Mesh refinement results, transverse component of velocity at Gauge 332...................34

Figure B7. Mesh refinement results, longitudinal component of velocity at Gauge 642..................35

Figure B8. Mesh refinement results, transverse component of velocity at Gauge 642 ...................35

Figure B9. Mesh refinement results, longitudinal component of velocity at Gauge 999. ................36

Figure B10. Mesh refinement results, transverse component of velocity at Gauge 999.................36

Figure D1. Sailing line and mesh boundaries for Pool 26............................................................ 40

Figure D2. Pool 26 boat file............................................................................................................. 41

Figure E1. Longitudinal and transverse velocity history, Gauge 040.............................................. 42

Figure E2. Longitudinal and transverse velocity history, Gauge 071. ........................................... 42

Figure E3. Longitudinal and transverse velocity history, Gauge 332 ..............................................43

Figure E4. Longitudinal and transverse velocity history, Gauge 642 ….......................................... 43

Figure E5. Longitudinal and transverse velocity history, Gauge 999.............................................. 44

\section{Tables}

Table 1. Example boat file card description.................................................................................... 12

Table 2. Flow velocity gauge locations. ............................................................................................ 14

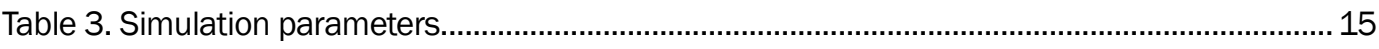

Table 4. Nozzle parameters.................................................................................................... 19 


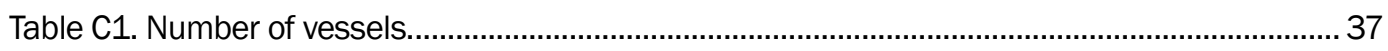

Table C2. Sailing line and initial vessel position....................................................................... 37

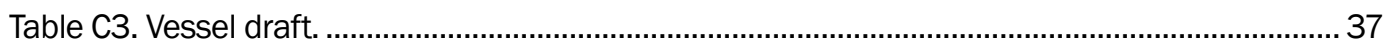

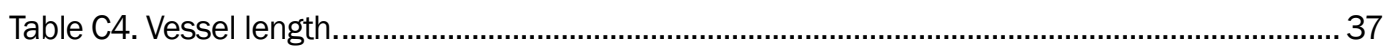

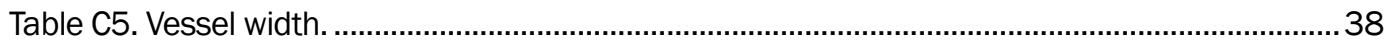

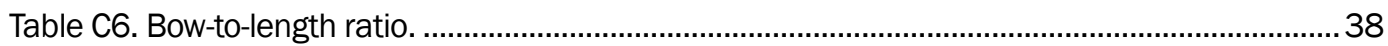

Table C7. Stern-to-length ratio. ........................................................................................................ 38

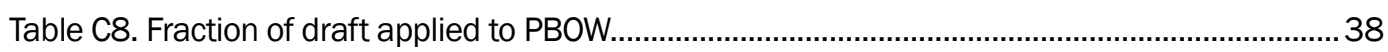

Table C9. Fraction of draft applied to PSTR.

Table C10. Sailing-line segment definition.................................................................................... 39

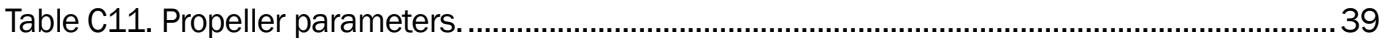

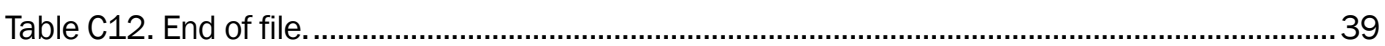

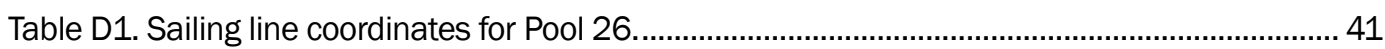

Table D2. Direction of turn data for Pool 26 ................................................................................. 41 


\section{Preface}

The research presented in this report was authorized by the Headquarters of the U.S. Army Corps of Engineers and sponsored by the Navigation Systems Research Program (NSRP). This work was conducted in the Coastal and Hydraulics Laboratory (CHL) of the U.S. Army Engineer Research and Development Center (ERDC) during the period October 2004 to September 2007 under the direction of Dennis W. Webb, Chief of Navigation Branch; Dr. Rose M. Kress, Chief of Navigation Division; Dr. William D. Martin, Deputy Director, CHL; and Thomas W. Richardson, Director, CHL.

This investigation of methods appropriate for modeling vessel-generated currents and shear stresses was conducted by Dr. Richard L. Stockstill and E. Allen Hammack, Navigation Branch, and David S. Smith, Estuarine Engineering Branch, CHL. Dr. R. C. (Charlie) Berger, Estuarine Engineering Branch, CHL, peer reviewed the report. The Program Manager for NSRP was James E. Clausner, CHL.

COL Richard B. Jenkins was Commander and Executive Director of ERDC. Dr. James R. Houston was Director. 


\section{Unit Conversion Factors}

\begin{tabular}{|l|c|l|}
\hline Multiply & By & To Obtain \\
\hline cubic feet & 0.02831685 & cubic meters \\
\hline cubic meters & 35.3 & cubic feet \\
\hline dynes $/ \mathrm{cm}^{2}$ & 0.1 & Pascals \\
\hline feet & 0.3048 & meters \\
\hline inches & 0.0254 & meters \\
\hline
\end{tabular}




\section{Introduction}

\section{Background}

The hydrodynamic effects of a vessel moving through a flow field significantly affect a navigation channel. The waves produced by moving vessels increase the rate of shoreline erosion and affect other vessels moving through the channel. Vessel movement induces shear stresses on the channel bed, which alters sediment transport and deposition patterns. Successful modeling of such effects provides a valuable tool for predicting the impact vessels have on the channel and other vessels.

The numerical model code developed in this research followed the methods that had been used in the original Upper Mississippi River Study (UMRS) conducted in the mid-to-late 1990s (Stockstill and Berger 1999). The current study improved on the former in that the numerical scheme employed mesh adaption and incorporated relations to calculate shear stresses on the bed induced by a moving vessel. The result is a single, efficient model developed to do the work that previously required several standalone models. The current research provides a method of computing the vessel-generated bed shear stresses using the algorithms and data presented by Maynord (2000). The empirical shear-stress relations given by Maynord (2000) rely on rules as to the direction the vessel travels relative to river currents. Rather than tuning the empirical parameters for a particular channel configuration and vessel size and speed, a combination of physics-based and empirical relations was deemed appropriate to solve the problem.

\section{Vessel effects}

Quantifying the effects of vessels sailing along a waterway is a complex problem because the flow is unsteady and the river bathymetry is nonuniform. These effects include: drawdown of the water surface, return currents around the vessel, and increased bed shear stresses and pressures that act to re-suspend the bed material and perhaps erode banks. Historically, studies to capture vessel effects required that the flow first be modeled, then the bed effects were computed, and finally, the fate of the bed material that is re-suspended was determined. A seamless modeling 
system would allow the hydraulic engineer conducting the study to focus more on model results and remediation than on the modeling process.

\section{Previous studies}

Flow fields associated with moving vessels have been simulated using the hydrodynamics code HIVEL2D. This model computes the vessel effects in conjunction with ambient conditions (Stockstill and Berger 1999, 2001; Stockstill et al. 1995). HIVEL2D uses an unstructured, static mesh wherein the vessel is simulated by a pressure field that moves through the waterway. The model produces current and water-surface knowledge such as drawdown and transverse stern waves. However, HIVEL2D requires a fine mesh throughout the entire sailing path of the vessel. The complicated meshes require long setup and long computing times, and the hydrodynamics is not coupled with any sediment transport simulator, which means the numerical model does not directly include sedimentation effects.

\section{Current approach}

The current study addresses these issues using the Adaptive Hydraulics (ADH) flow solver. The shallow-water module of ADH solves the depthaveraged two-dimensional (2D) flows using serial or parallel processing. However, one of the most beneficial attributes of $\mathrm{ADH}$ is the adaptive mesh technique, which gives it the capability of refining or coarsening the mesh based on error estimates during flow calculations (Tate et al. 2006). Similar to HIVEL2D, the vessel effects are modeled in ADH by moving a pressure field through the flow. Due to mesh adaption abilities, the code is able to improve upon the previous technique by reducing computational times. Mesh refinement can be limited to the vessel vicinity even though the position changes with time. Berger and Lee (2005) have documented the mesh adaption algorithms and, in particular, their application to modeling moving vessels. As a vessel approaches a region within the channel, the mesh in that region is refined for the calculations in the more complex flow. As the vessel continues past that point, the mesh is then coarsened. This automated mesh adaption reduces the cost of studying the impact vessels have in confined waterways. Because the refinement indicator is determined by the flow variables, $\mathrm{ADH}$ will adapt any region in which the flow is strongly disturbed. Generally this will be in the area near the vessel. However, if the vessel-induced waves are still significant at some distance away, ADH will recognize this and adapt. 
Given input including boundary conditions, computational meshes, and vessel parameters, $\mathrm{ADH}$ produces a resulting flow field and water-surface elevation by providing a finite-element solution to the $2 \mathrm{D}$ shallow-water equations. ${ }^{1}$ As the vessel moves along a prescribed sailing line, the effect of its pressure field causes changes in the flow field. ADH returns the computed shear stress as a series of scalar values as it does with other output variables (residual, depth, and velocity components). The shear stresses can be used to compute sediment entrainment, and the computed flow field can be used to model sediment transport.

Garcia et al. (2002) and Maynord (2000) have studied vessel-generated stresses on the bed; Maynord's research was selected as having the most appropriate results to incorporate into a numerical flow code to predict the bed shear stresses that lead to sediment entrainment and thus, transport. The current research is tasked with combining the flow model that represents the vessel effects with a sediment-transport model using a library system. The bed shear stresses associated with a vessel moving through a waterway are quantified using empirical relations developed from laboratory studies. The following paragraphs describe the essence of Maynord's report. In various regions near a vessel, the bed shear stress is rapidly increased due to the presence of a vessel sailing over or near the particular region. These regions are the focus of Maynord's study and are divided into areas where the stresses are attributed to the vessel's bow and to the propeller wash.

The approach Maynord (2000) uses to calculate the vessel-generated bed shear stresses requires knowledge of whether the vessel is upbound (moving in a direction opposite to ambient currents) or downbound. This method was used in the Upper Mississippi River Study (Maynord 2000) and by Garcia et al. (2002) to quantify the vessel effects. Applications using this method require knowledge about ambient current directions. A 2D flow model capable of simulating vessel-induced bed shear stress and thus sediment re-suspension and bank erosion must rely on a more general approach to quantify the shear stress.

A more practical method is one that uses a single empirical relation for the bed shear stress in both critical areas, at the bow and propeller, as functions of fluid velocity and vessel speed. Employing this method required

\footnotetext{
1 Appendix A includes a listing and brief discussion of the shallow-water equations.
} 
modification of the drag coefficients found by Maynord (2000), but the resulting algorithm does not require knowledge of vessel traveling direction (i.e., "upbound" or "downbound"). 


\section{Modeling Vessel-Generated Waves and Currents}

\section{Modeling method}

Vessel-generated currents and waves are modeled using the 2D unsteady shallow-water equations. These equations, presented in Appendix A, are depth-averaged equations of fluid motion that assume the pressure distribution is hydrostatic. The shallow-water equations are capable of resolving the long-period vessel effects attributed to both shallow-draft vessels (Stockstill and Berger 2001) and deep-draft vessels (Maynord 2003).

Investigators have calculated the effects of a vessel sailing through a waterway using the numerical hydraulic code, HIVEL2D. However, this model is computationally limited by longer setup and computational times than are now necessary. Also, HIVEL2D does not include sedimentation effects. The present study moves the concept of a moving pressure field, currently in HIVEL2D, into the modern ADH. Also, the sediment entrainment due to drawdown and vessel propellers is incorporated into ADH.

Previous studies have relied on fixed-mesh methods to model the vessel. The difficulty with this method is that the fine mesh resolution needed to define the vessel is required along the entire sailing line. This resolution requires more effort in generating the finite element mesh and significantly increases computational time. As its name implies, ADH applies mesh adaption techniques, which are based on a residual computed for each time step, to refine and coarsen a mesh based on flow complexity.

\section{Initial mesh resolution and adaption}

A major principle of computational modeling is that a model will converge to the governing equations as the resolution is increased. This level of mesh detail is usually defined by a mesh convergence testing. With an adaptive mesh model, convergence testing is made easier because mesh refinement is done automatically during a simulation.

Setting up a moving-vessel model in $\mathrm{ADH}$ requires a mesh that adequately describes the bathymetry. Ideally, the mesh should only be fine enough to 
provide ADH convergence. The initial solution accuracy is not important at this point since this solution will be used to determine appropriate adaption parameters for subsequent runs.

The first step in creating a mesh for vessel movement is to determine the sailing line that the vessel will travel. The sailing line may consist of an unlimited number of line segments and arcs. As the vessel moves from one segment in the sailing line to another, the vessel is turned immediately about its centroid. The transition from one segment to the next should be smooth to avoid any sudden, large turns. Similarly, the radius of any arc sections of the sailing line should be large. While the sailing line defines where a vessel moves within a flow field, the sailing line is not required to begin or end within the mesh boundaries. If the sailing line does extend beyond the mesh boundaries, the vessel will sail "into" or "out of" the mesh during a simulation. Solution convergence is difficult as the vessel traverses a mesh boundary in those cases.

The 2D mesh can be described in terms of longitudinal and lateral element sizes. Here, "longitudinal" means along the vessel's sailing line, and "lateral" means normal to the vessel's sailing line. The primary region of interest is the area in the immediate vicinity of the vessel, the near field. "Near" refers to a rectangular area centered on the vessel center and extending half a vessel width on either side of the vessel and half a vessel width forward and aft of the vessel. The vessel width is taken as the width of the vessel at its widest point.

A test scheme was developed to address the lateral mesh resolution required both under the vessel and in the near field at the port and starboard sides. The vessel was centered laterally on a prescribed sailing line, and the number of elements under the vessel was varied sequentially from two to eight. Similarly, the number of elements in the near region of the side of the vessel was ranged from two to eight. Meshing guidelines for simulating vessel movement in HIVEL2D (Stockstill and Berger 1999) fell in within the chosen scheme. Solutions were generated with each test mesh. The coarsest mesh for which ADH converged indicates the level of lateral refinement required for the initial mesh. ADH converged for each test; therefore, two elements should span the vessel width with one element spanning the near-field region on either side of the vessel. This level of refinement should be used around any possible sailing line of each vessel being simulated. 
The number of elements that span the vessel length is related to the elements spanning the boat width by the element aspect ratio (AR) defined by:

$$
A R=\frac{L_{e}}{W_{e}}
$$

where:

$$
\begin{aligned}
L_{e} & =\text { element length } \\
W_{e} & =\text { element width. }
\end{aligned}
$$

The element aspect ratio should be about 3 or less. Previous studies (Stockstill and Berger 1999) have shown that an element length of onethird of the vessel length is sufficient. These element sizes are only suggestions for the initial mesh resolution. If these elements are too large, ADH can refine them. Figure 1 shows the recommended resolution for the coarse mesh around the sailing line. Note there are two elements covered laterally by the vessel footprint and three elements longitudinally.

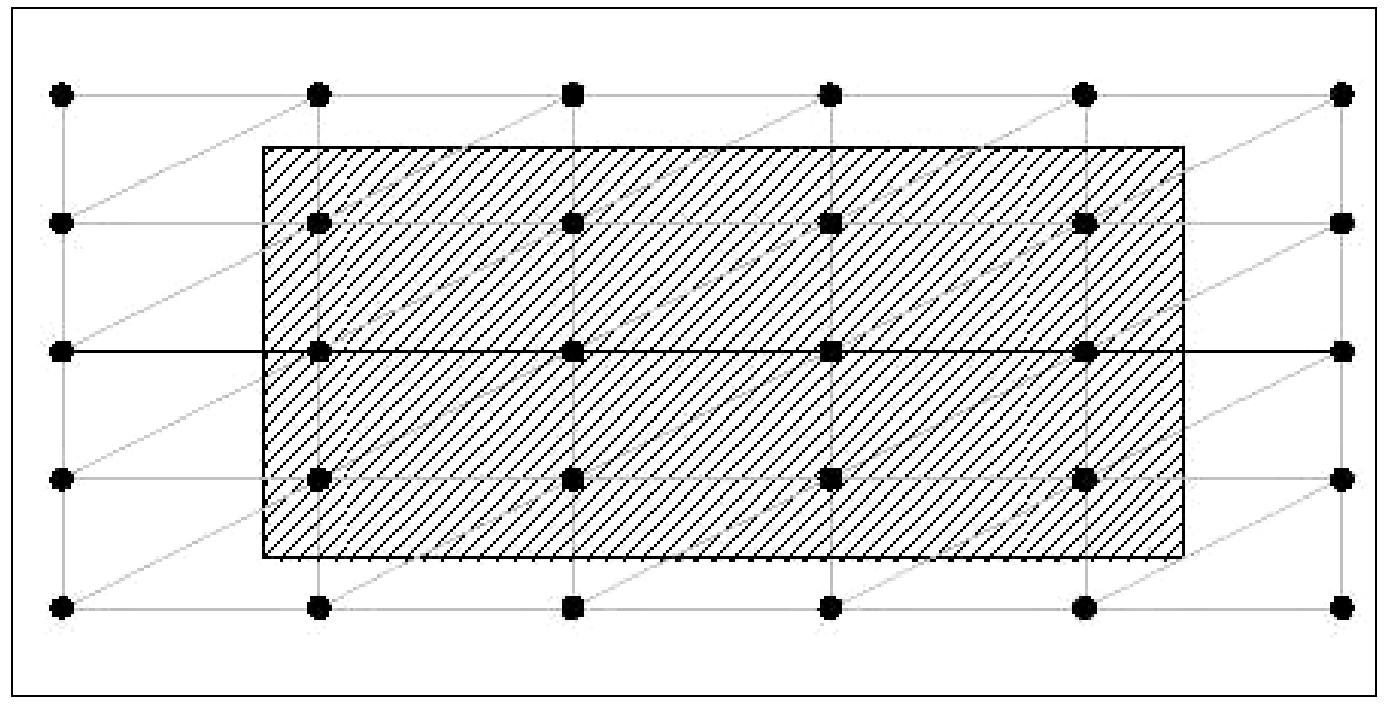

Figure 1. Recommended resolution for the initial mesh.

One final parameter that is somewhat independent of the actual physics is the length of the time step chosen for the simulation. The time step should be set so the vessel advances one element length per time step. Thus, the length of the time step $(\Delta t)$ is calculated as: 


$$
\Delta t=\frac{L_{e}}{V_{g}}
$$

where:

$$
V_{g}=\text { vessel velocity relative to ground. }
$$

Figure 2 illustrates a vessel advancing by one element length in one time step. The nodes along the sailing line are shown in red, and the vessel is moving from left to right. Note that, at time $t$, there are two nodes along the sailing line ahead of the vessel and one aft. At the next time step, time $t+\Delta t$, there is only one node along the sailing-line ahead of the vessel and two aft.

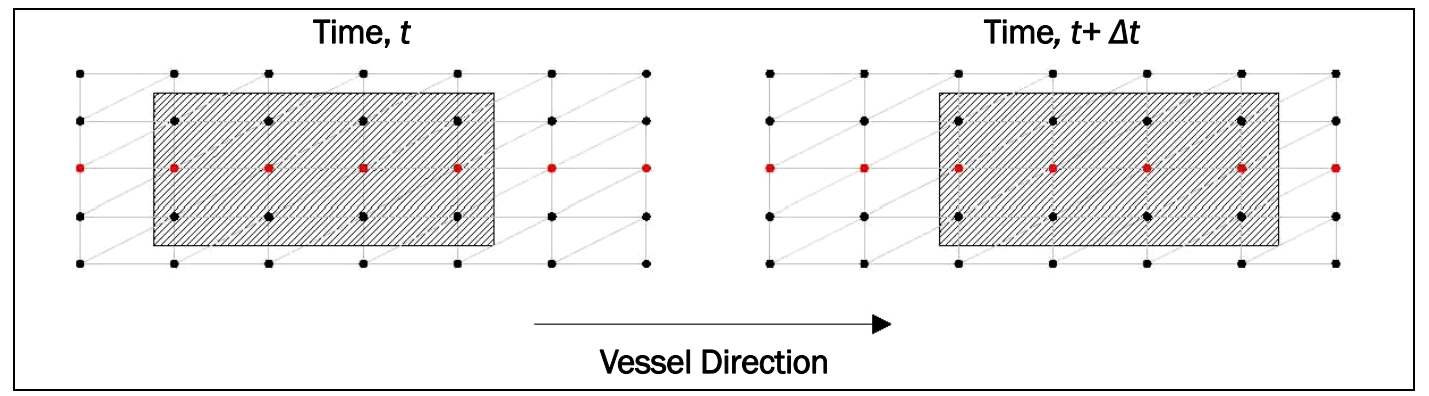

Figure 2. Time step selection for vessel movement.

Note that, in Figure 2, the elements near the sailing line are right triangles. Although the elements are not required to be right triangles, the watersurface elevation contours from a simulation show a vessel footprint that is much more reflective of the actual shape of the vessel than if the elements are arbitrarily shaped.

Once an initial coarse mesh is created and an initial simulation complete, adaption parameters can be set. ADH uses two user-defined parameters, the refinement tolerance and the maximum number of adaption levels, to control the amount of refinement during a simulation. The refinement tolerance value acts as a "trigger" value for $\mathrm{ADH}$ to determine the elements that will be refined. $\mathrm{ADH}$ compares the refinement tolerance to the residual calculated for each element. If the residual is larger than the refinement tolerance, the element will be refined; otherwise, no adaption occurs. The refinement tolerance should be set to 1.0 for the initial simulation because $\mathrm{ADH}$ scales the residual values by the refinement tolerance. These scaled residuals are written to the error output file (*_err.dat). 
Two different attempts were made to define a refinement tolerance that would only refine the mesh near the vessel. In the first attempt, the largest residual on the boundary of the near-field region was used as the refinement tolerance. The largest residual was typically found at the stern. This refinement tolerance value resulted in refinement within the vessel footprint, but did not produce enough refinement around the vessel. The second attempt was to use an average residual value for nodes away from the vessel to specifically not refine the elements in the far field, but to refine the elements around the vessel. Since the residual is drastically lower in regions far from the vessel, a representative number greater than that residual should be an adequate mesh refinement tolerance. Using a far-field residual value as the mesh refinement tolerance, $\mathrm{ADH}$ refined the mesh only within the near-field region. Thus, a sufficient refinement tolerance value was determined.

Figure 3 shows the section of the mesh containing the vessel. The top picture shows the initial, unadapted mesh, and the bottom picture shows the adapted mesh. The adaption only extends one-half of the vessel width laterally from the vessel whereas the entire vessel footprint has been refined by at least one level. The longitudinal refinement is limited to about one-third of the vessel length ahead of the vessel and one-half of the vessel length aft the vessel. Two levels of refinement are required only at the bow and stern. This method of choosing a mesh refinement tolerance is recommended for vessel movement simulations.

A mesh refinement study was conducted to determine the necessary number of adaption levels required to adequately model vessel movement. Using a refinement tolerance chosen using the far-field node method, analyses were conducted until the solutions converged.

Plots of both the transverse and longitudinal velocity data for the different refinement levels showed that the solution converged with two levels of refinement. Appendix B shows mesh convergence plots for a simulation performed to compare model results to field tests, which will be discussed in more detail in later paragraphs. 


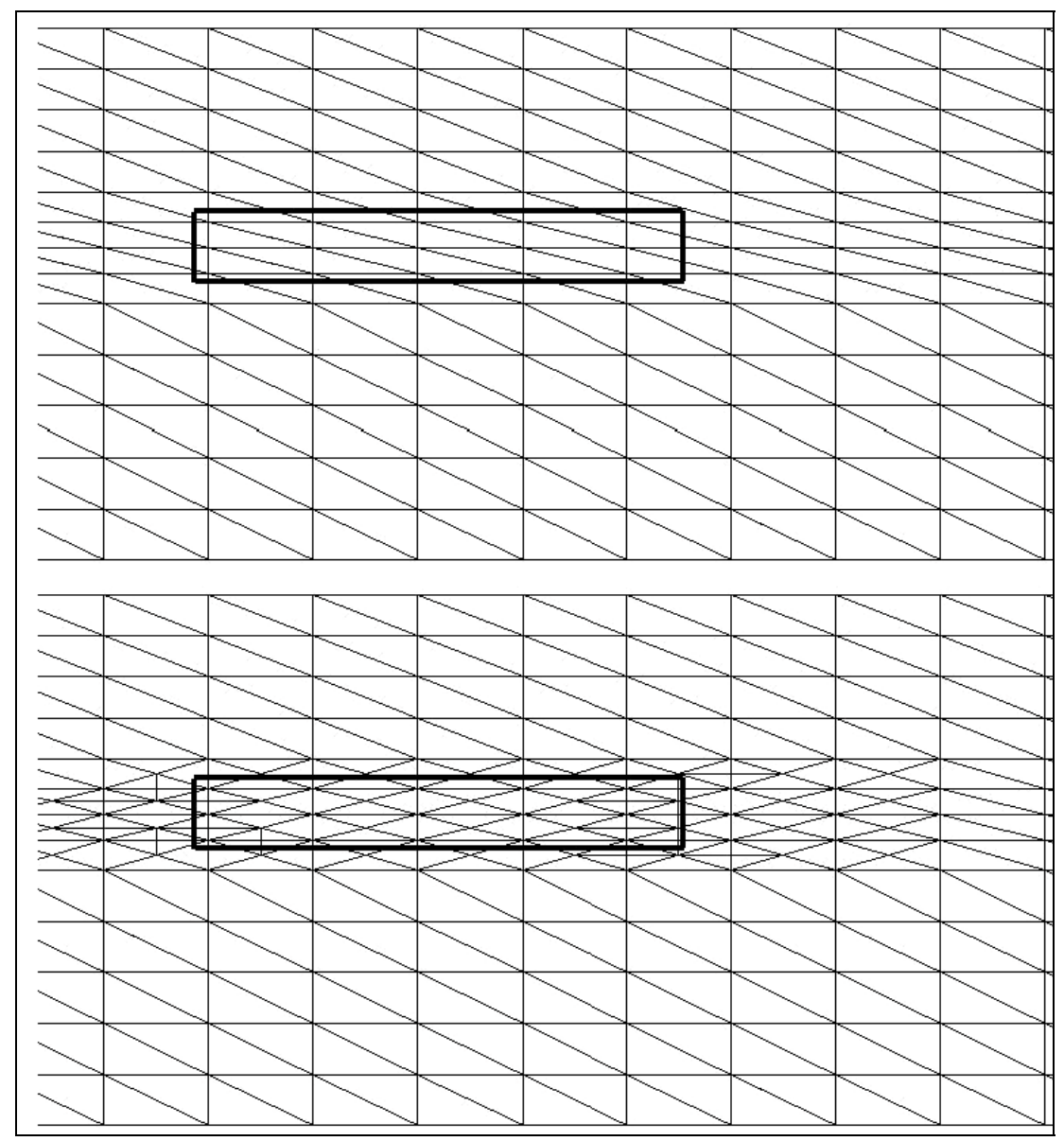

Figure 3. Mesh adaption around the vessel.

Figure 4 illustrates the convergence plots showing transverse flow velocities as the vessel passes a location in the flow. There is no change in the flow solution for more than two levels of adaption, indicating that only two levels of adaption were required to drive the residual to a value less than the specified refinement tolerance. The velocity at the other locations showed a similar convergence pattern, so two levels of refinement should be used for a vessel simulation.

In summary:

- The elements in the vessel's near-field region should be about one-half of the vessel-width wide and one-third of the vessel-length long.

- The mesh refinement tolerance should be set to an average value of the residual at nodes far from the vessel.

- The number of levels of refinement should be set to two. 


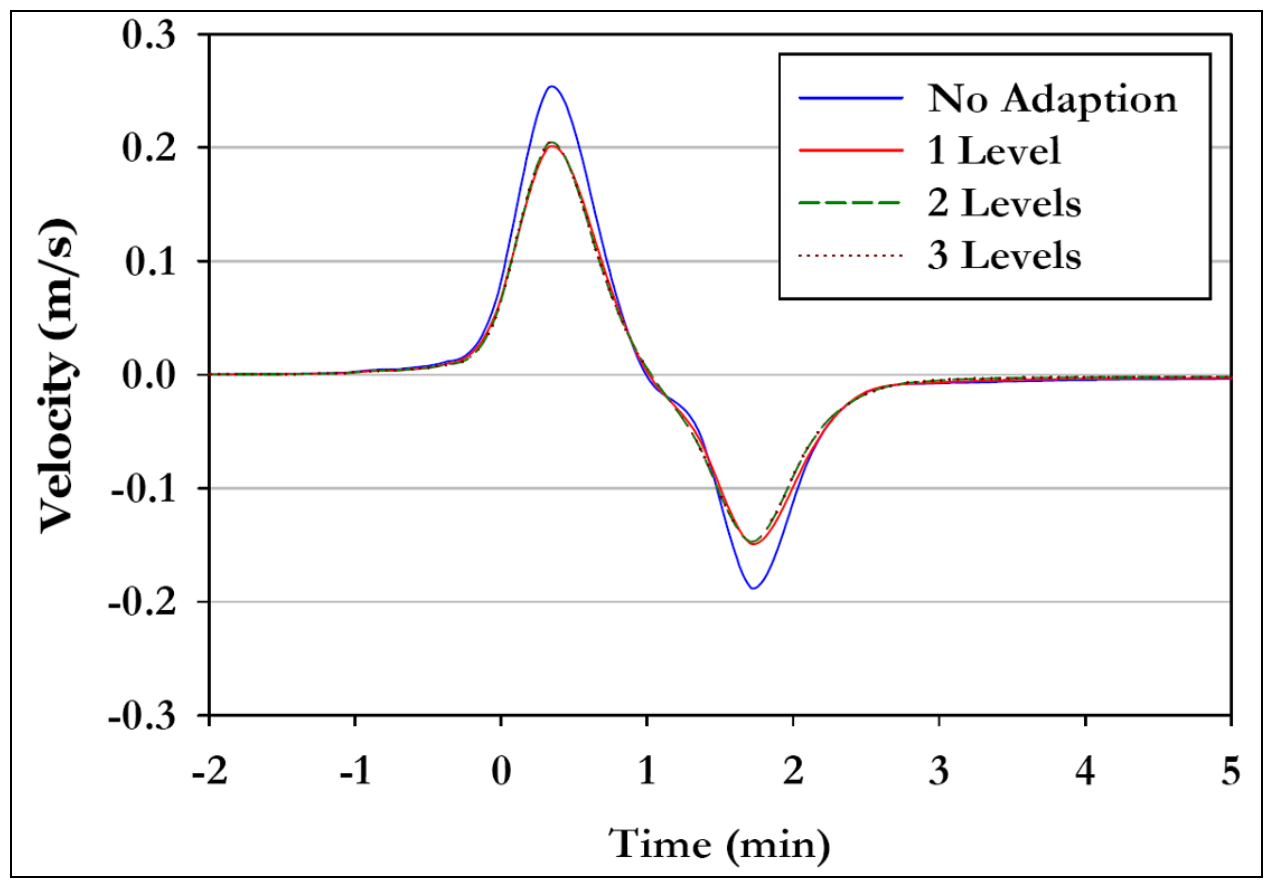

Figure 4. Example flow velocity mesh convergence.

\section{Vessel definition}

A boat ( ${ }^{*}$.bt) file containing the vessel parameters must be defined for vessel effects simulations and placed in the project directory. Appendix $\mathrm{C}$ summarizes the necessary lines for the boat file. The data in Table 1 describe each line in the example boat file shown in Figure 5. The boundary condition (*.bc) file must include a line containing the "OP BT" card to indicate a vessel simulation. Figure 5 shows an example boat file for two vessels moving from opposite ends of a channel. (Appendix D gives an additional example of a boat file.) The "vessels" described are threewide by four-long barge tows.

\section{Initial vessel location}

For simulations involving only one vessel, the vessel should be placed completely within the flow field at the beginning of a simulation (i.e., the vessel should be not placed so it sails "into" the flow field). Convergence is much more likely if the vessel is initially within the flow field. The first coordinate of the sailing line defines the initial location of the vessel centroid, so this coordinate should be far enough into the flow field that the stern is within the mesh boundaries. After the vessel is placed on the mesh, a simulation should be run with a stationary vessel long enough to 
Table 1. Example boat file card description.

\begin{tabular}{|c|c|}
\hline Example Line & Meaning \\
\hline BOAT 2 & Two vessels will be simulated. \\
\hline FDEF $11-119.0-1.52 .9$ & $\begin{array}{l}\text { The sailing line for Vessel } 1 \text { has one segment beginning at }(-119.0 \text {, } \\
-1.5) \text {, and the vessel begins with an initial velocity of } 2.9 \mathrm{~m} / \mathrm{s} \text {. }\end{array}$ \\
\hline DRFT 12.74 & The draft of Vessel 1 is $2.74 \mathrm{~m}$. \\
\hline BLEN 1257 & The length of Vessel 1 is $257 \mathrm{~m}$. (Total length of barges in tow) \\
\hline BWID 132 & The width of Vessel 1 is $32 \mathrm{~m}$. (Total width of barges in tow.) \\
\hline PBOW 10.1 & For Vessel 1 , the ratio of the bow length to the vessel length is 0.1 . \\
\hline PSTR 10.1 & For Vessel 1 , the ratio of the stern length to the vessel length is 0.1 . \\
\hline CBOW 10.95 & For Vessel 1, the fraction of the draft applied over PBOW is 0.95 . \\
\hline CSTR 10.95 & For Vessel 1, the fraction of the draft applied over PSTR is 0.95. \\
\hline PROP 122.746525 & $\begin{array}{l}\text { The propellers for Vessel } 1 \text { have } 2.74 \mathrm{~m} \text { diameter Kort nozzles } \\
\text { spaced } 6 \mathrm{~m} \text { apart. The towboat length is } 52 \mathrm{~m} \text {, and the propellers } \\
\text { are } 5 \mathrm{~m} \text { from the stern. }\end{array}$ \\
\hline SDEF $110-3080.0-1.52 .9$ & $\begin{array}{l}\text { For Vessel } 1 \text {, the first segment of the sailing path is a line ending at } \\
(-3080.0,-1.5) \mathrm{m} \text {, and the vessel begins with an initial velocity of } \\
2.9 \mathrm{~m} / \mathrm{s} \text {. }\end{array}$ \\
\hline FDEF $21-6955.0-1.52 .9$ & $\begin{array}{l}\text { The sailing line for Vessel } 2 \text { has one segment beginning at (-6955.0, } \\
-1.5) \text {, and the vessel begins with an initial velocity of } 2.9 \mathrm{~m} / \mathrm{s} \text {. }\end{array}$ \\
\hline DRFT 22.74 & The draft of Vessel 2 is $2.74 \mathrm{~m}$. \\
\hline BLEN 2257 & The length of Vessel 2 is $257 \mathrm{~m}$. \\
\hline BWID 232 & The width of Vessel 2 is $32 \mathrm{~m}$. \\
\hline PBOW 20.1 & For Vessel 2 , the ratio of the bow length to the vessel length is 0.1 . \\
\hline PSTR 20.1 & For Vessel 2, the ratio of the stern length to the vessel length is 0.1 . \\
\hline CBOW 20.95 & For Vessel 2, the ratio of the bow length to the vessel draft is 0.95 . \\
\hline CSTR 20.95 & $\begin{array}{l}\text { For Vessel 2, the ratio of the stern length to the vessel length is } \\
0.95 \text {. }\end{array}$ \\
\hline PROP 212.746525 & $\begin{array}{l}\text { The propellers for Vessel } 2 \text { have } 2.74 \mathrm{~m} \text { diameter open wheel } \\
\text { nozzles spaced } 6 \mathrm{~m} \text { apart. The towboat length is } 52 \mathrm{~m} \text {, and the } \\
\text { propellers are } 5 \mathrm{~m} \text { from the stern. }\end{array}$ \\
\hline SDEF $210-3744.0-1.52 .9$ & $\begin{array}{l}\text { For Vessel } 2 \text {, the first segment of the sailing path is a line ending at } \\
(-3744.0,-1.5) \mathrm{m} \text {, and the vessel begins with an initial velocity of } \\
2.9 \mathrm{~m} / \mathrm{s} \text {. }\end{array}$ \\
\hline ENDD 00 & End of file. \\
\hline
\end{tabular}




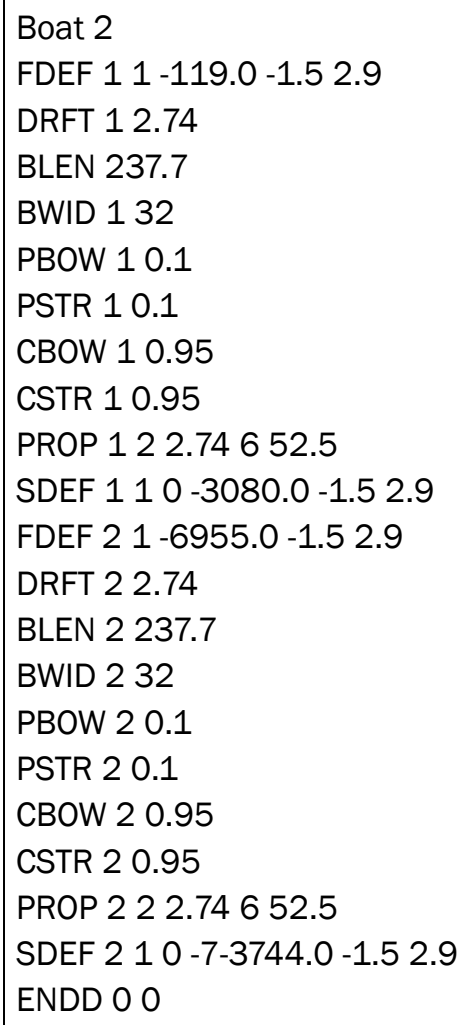

Figure 5. Example boat file.

dissipate the initial flow disturbances. Depending on the magnitude of the vessel velocity, gradually increasing the velocity to its maximum may be required.

Inserting the vessel into the flow field with its full draft will disrupt the flow field considerably and could cause ADH to diverge. If, for a certain channel, ADH does not converge using the full vessel draft, a vessel draft smaller than the actual draft may be used initially. Using the final depth and velocity values in the *_dep.dat and *_vel.dat files as the new initial flow conditions, the draft can be increased and a new simulation run. This procedure should be followed until a simulation with the full vessel draft is completed.

For simulations with multiple vessels, especially simulations over very long periods of time, some vessels may not begin a simulation in the flow field and will enter at some time during the simulation. 


\section{Multiple vessel considerations}

$\mathrm{ADH}$ is capable of modeling multiple vessels within the flow field. Analyses with multiple vessels that move through the mesh at different times can be performed without extending the mesh to the appropriate starting location for each vessel. The sailing line for each vessel can be extended outside the mesh boundaries. The first segment in each sailing line should be set to where vessel will enter the mesh at the appropriate time while traveling at the specified velocity.

\section{Model testing}

A study was performed to determine how well the $\mathrm{ADH}$ calculations compared to field data of a 3-wide by 4-long barge train taken from Bhowmik et al. (1993). The flow velocity was calculated at five points along a cross section of the river, corresponding to actual field gauge locations. Table 2 lists the lateral location of each gauge from the thalweg. Negative distances are to the left of the sailing line looking downstream and positive distances to the right.

Table 2. Flow velocity gauge locations.

\begin{tabular}{|l|l|}
\hline Gauge & Lateral Location $(\mathrm{m})$ \\
\hline 071 & -108 \\
\hline 040 & -60 \\
\hline 332 & 69 \\
\hline 642 & 87 \\
\hline 999 & 100 \\
\hline
\end{tabular}

Figure 6 schematically illustrates the channel cross-section showing the gauge locations relative to the vessel. The model results are depthaveraged values, so the depth of the field gauges is not taken into account. Table 3 lists the physical parameters of the model conditions.

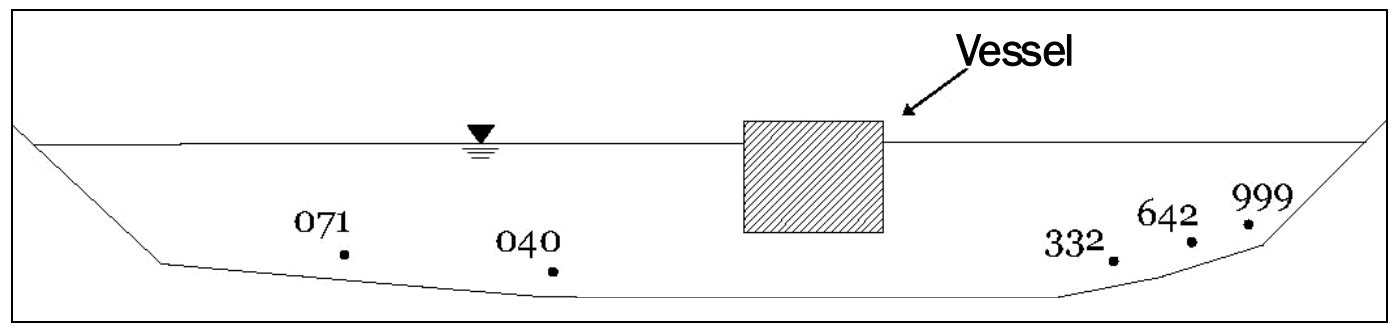

Figure 6. Channel cross-section showing gauge locations relative to the vessel. 
Table 3. Simulation parameters.

\begin{tabular}{|l|l|}
\hline Total Vessel Length $(\mathrm{m})$ & 237.7 \\
\hline Total Vessel Width $(\mathrm{m})$ & 32 \\
\hline Draft $(\mathrm{m})$ & 2.74 \\
\hline Vessel Velocity $(\mathrm{m} / \mathrm{s})$ & 2.9 \\
\hline Channel Flow Rate $\left(\mathrm{m}^{3} / \mathrm{s}\right)$ & 628 \\
\hline Tailwater Elevation $(\mathrm{m})$ & 4.7 \\
\hline Manning's $\mathrm{n}$ & 0.025 \\
\hline Time Step $(\mathrm{s})$ & 20.8 \\
\hline Levels of Adaption & 2 \\
\hline
\end{tabular}

Figure 7 shows velocity histories comparing ADH results and field data. Both the longitudinal and transverse velocities are those at Gauge 999. The time on this plot has been translated, such that the origin corresponds to the time at which the vessel bow passes the gauge locations.

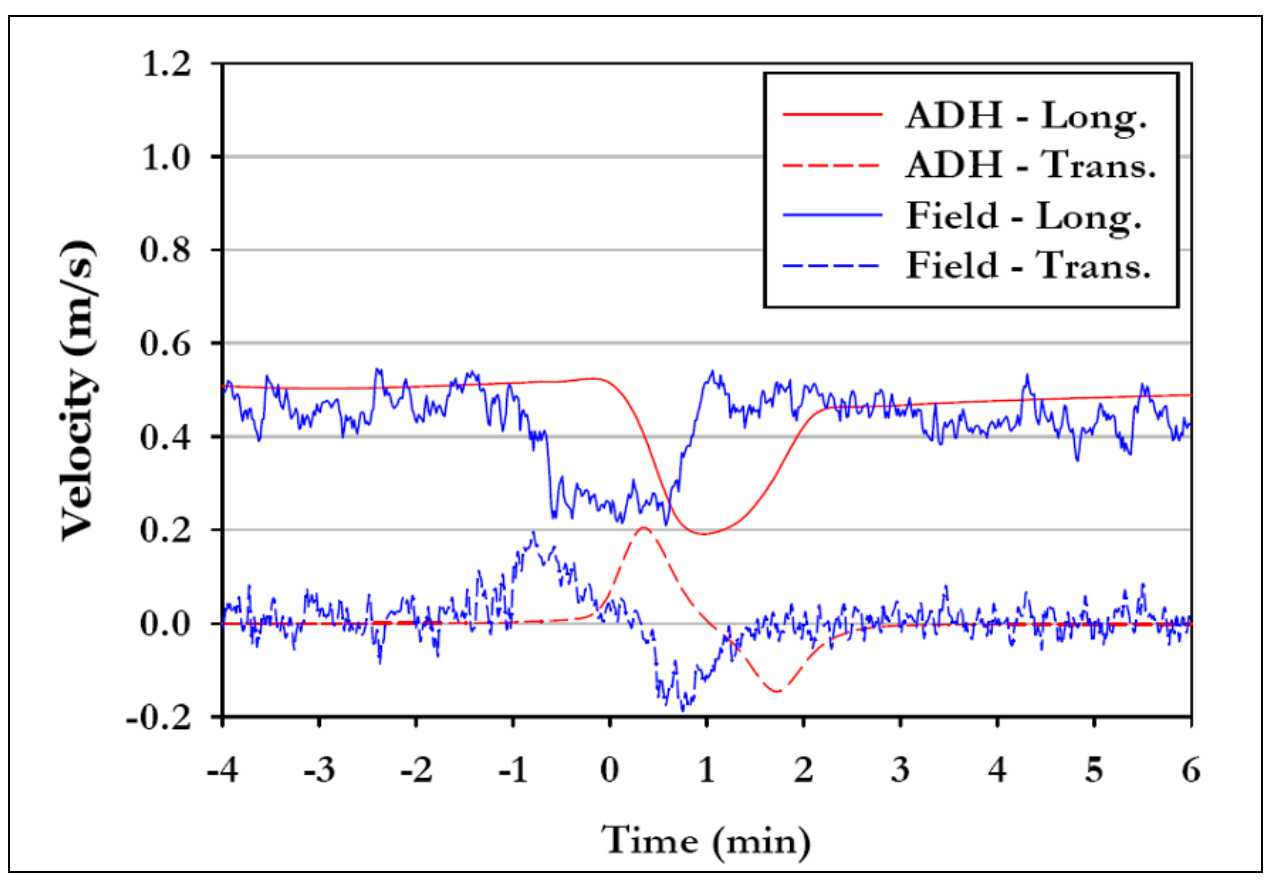

Figure 7. Velocity comparison of ADH results and field data.

The simulation data captures the low-frequency wave behavior in both the longitudinal and transverse directions very well. The error in the timing of peak values has been attributed to the field data not being properly offset to the time the bow crosses the gauges. Appendix E includes comparison plots of $\mathrm{ADH}$ and field data at each gauge location. 


\section{Vessel-Generated Bed Shear Stresses}

The empirical relations developed by Maynord (2000) and Garcia et al. (2002) describe the shear stresses in terms of cross-sectional flow variables. General or averaged cross-sectional values such as flow velocity and depth are not readily available in a multi-dimensional model. A particular location in a 2D model has knowledge of local flow variables such as the flow depth and velocity only.

\section{Vessel-induced bed shear stress relations}

Vessel-induced bed shear stress relations were originally developed to account for a vessel traveling either upstream or downstream. A series of equations has been formulated using the Maynord (2000) data for the peak bow stress that does not require the up- or downstream condition. The bed shear stresses induced by the vessel are broken down into two different parts: those induced by the bow and those induced by the propellers. Each shear stress relation follows the same general formulation with the shear stress directly related to the fluid density and the square of a characteristic fluid velocity.

\section{Bow effects}

The bed shear stress induced by the bow ( $\tau_{b o w}$ ) has been related to the vessel velocity by:

$$
\tau_{b o w}=\frac{1}{2} \rho C_{b o w} V_{g}^{2}
$$

where:

$$
\begin{aligned}
\rho & =\text { fluid density } \\
V_{g} & =\text { vessel velocity relative to the ground } \\
C_{b o w} & =\text { bow correction coefficient. }
\end{aligned}
$$

The bow correction coefficient $\left(C_{\text {bow }}\right)$ is an empirical function of only the depth-to-draft ratio as: 


$$
C_{\text {bow }}=0.068\left(\frac{\text { depth }}{\text { draft }}\right)^{-1.29}
$$

Here, the depth-to-draft ratio is computed using local values as:

$$
\frac{d e p t h}{d r a f t}=\frac{h+P}{d}
$$

where:

$$
\begin{aligned}
& h=\text { flow depth under the vessel } \\
& P=\text { pressure head induced by the vessel } \\
& d=\text { vessel draft. }
\end{aligned}
$$

The pressure head $(P)$ induced by the vessel is calculated as:

$$
P=\frac{p}{\rho g}
$$

where:

$$
\begin{aligned}
& p=\text { pressure on the water surface representing the vessel } \\
& g=\text { acceleration due to gravity. }
\end{aligned}
$$

\section{Propeller effects}

The propeller-induced bed shear stress $\left(\tau_{\text {prop }}\right)$, caused by the accelerated flow exiting the propellers, is calculated as:

$$
\tau_{\text {prop }}=\frac{1}{2} \rho C_{f s} V_{\text {shear }}^{2}
$$

where:

$$
\begin{aligned}
C_{f s}= & \text { skin friction coefficient } \\
V_{\text {shear }}= & \text { velocity used in the calculation of the propeller-induced bed } \\
& \text { shear stress. }
\end{aligned}
$$

The skin friction coefficient $\left(C_{f s}\right)$ of the propeller is calculated as: 


$$
C_{f s}=0.01 \frac{D_{\text {prop }}}{H_{\text {prop }}}
$$

where:

$D_{\text {prop }}=$ propeller diameter

$H_{\text {prop }}=$ depth under the propeller.

The depth under the propeller $\left(H_{p r o p}\right)$ is defined as the distance from the center of the propeller to the channel bottom or:

$$
H_{\text {prop }}=h-\frac{1}{2} D_{\text {prop }}
$$

As shown in Figure 8, this relationship assumes that the propeller is essentially at the water surface. This assumption is valid for the barge trains used to develop the bed shear stress relations given in this report.

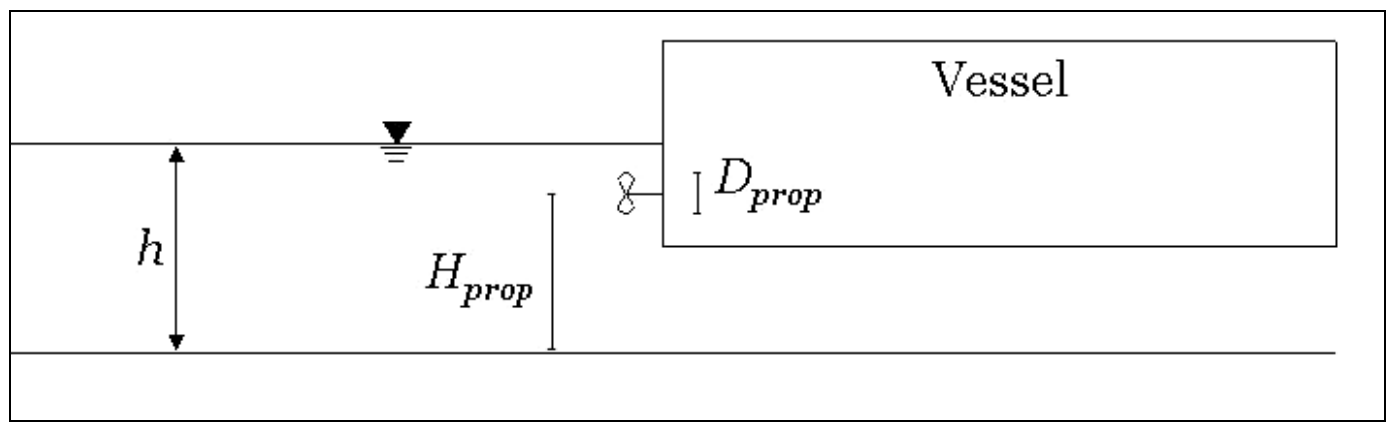

Figure 8. Schematic of propeller terms.

The velocity used in the calculation of the propeller-induced bed shear stresses is defined as:

$$
V_{\text {shear }}=\left|V_{\text {prop }}\right|+\frac{1}{2}\left|V_{\text {wake }}\right|
$$

where:

$V_{\text {prop }}=$ maximum bottom velocity from the propeller relative to the vessel

$V_{\text {wake }}=$ wake velocity . 
The maximum bottom flow velocity from the propeller relative to the vessel is given by:

$$
V_{\text {prop }}=E V_{\text {jet }} f \frac{D_{\text {prop }}}{H_{\text {prop }}}
$$

where:

$$
\begin{aligned}
E= & \text { empirical constant related to the nozzle type } \\
V_{j e t}= & \text { velocity of the jet produced by the propeller } \\
f= & \text { constant related to the increase in jet velocity caused by the } \\
& \text { propeller velocity and geometry. }
\end{aligned}
$$

The constant $f$ is defined as:

$$
f= \begin{cases}q, & V_{j e t} \neq 0 \text { and } q>0 \\ 0, & \text { otherwise }\end{cases}
$$

where $q$ is:

$$
q=1-C\left|\frac{V_{g}}{V_{\text {jet }}}\right|\left(\frac{H_{\text {prop }}}{D_{\text {prop }}}\right)^{1.5}
$$

where values for $C$ are given in Table 4 .

Table 4. Nozzle parameters.

\begin{tabular}{|l|l|l|l|l|l|l|}
\hline Nozzle Type & $D_{0}$ & $E$ & $C$ & $P(\mathrm{hp})$ & $A_{1}$ & $A_{2}$ \\
\hline Open Wheel & $0.71 D_{\text {prop }}$ & 0.43 & 0.50 & 4550 & 23.57 & 2.3 \\
\hline Kort & $D_{\text {prop }}$ & 0.58 & 0.25 & 3780 & 31.82 & 5.4 \\
\hline
\end{tabular}

Note that the factor $f$ cannot be negative, and therefore cannot decrease the maximum bottom velocity from the propeller relative to the vessel. The velocity of the jet produced by the propeller, $V_{\text {jet }}$, is given by:

$$
V_{\text {jet }}=\frac{1.13}{D_{o}} \sqrt{\frac{T_{p r o p}}{\rho}}
$$


where:

$$
\begin{aligned}
D_{o}= & \text { the jet diameter at the location of maximum contraction of the } \\
& \text { jet. (Table } 4 \text { lists expressions for } D_{o} \text {.) }
\end{aligned}
$$

The thrust is solely dependent on the vessel velocity relative to the ambient flow and the power of the propeller engines. This relationship is characterized by Toutant's (1982) equation:

$$
T_{\text {prop }}=A_{1} P_{v e s}^{0.974}-A_{2} V_{w}^{2} \sqrt{P_{v e s}}
$$

where:

$$
\begin{aligned}
T_{\text {prop }} & =\text { thrust per propeller } \\
P_{\text {ves }} & =\text { total vessel power }(\mathrm{in} \mathrm{hp}) \\
V_{w} & =\text { vessel velocity relative to the flow }(\text { in } \mathrm{mi} / \mathrm{hr}) \\
A_{1}, A_{2} & =\text { empirical constants. }
\end{aligned}
$$

The vessel power and the constants $A_{1}$ and $A_{2}$ depend on the type of nozzle on the propeller. Table 4 lists the values for all constants required to calculate the propeller-induced bed shear stresses for both open-wheel and Kort nozzles. The maximum wake velocity relative to the ambient flow velocity is given by:

$$
V_{\text {wake,max }}=-0.78 V_{g}\left(\frac{\text { depth }}{\text { draft }}\right)^{-1.81}
$$

Each nozzle parameter in the shear stress model has now been introduced and defined. Table 4 lists the nozzle parameter values used in the model as reported by Maynord (2000).

The wake velocity decays with distance from the vessel; however, the decay rate for the phenomenon remains a research topic. As a matter of completeness and for simplicity, a linear rate-of-decay of wake velocity is assumed. The decay rate $\left(\beta_{\text {wake }}\right)$ is defined as:

$$
\beta_{\text {wake }}=1-0.075 \frac{H_{\text {prop }}}{\text { draft }}
$$


The wake velocity astern of the vessel is given by:

$$
V_{\text {wake }}=V_{\text {wake, } \max } \beta_{\text {wake }}+V_{a}
$$

where:

$$
V a=\text { ambient velocity ahead of the vessel. }
$$

\section{Vessel-averaged pressure and velocity}

Vessel-induced forces on the bed are dependent on the depth-to-draft ratio. This ratio, defined in Equation 5, requires a single value for the pressure head at the vessel. Multiple nodes fall within the vessel footprint, and each one has a unique pressure. A single value of pressure head is needed to compute bed shear stresses, so they must be combined in some way. To obtain a single value, the pressure head is calculated for 15 different locations within the vessel footprint (Figure 9). The pressure head for the vessel is the weighted average of the pressure head of each of the 15 points and the area of the section of the vessel footprint in which each point lies.

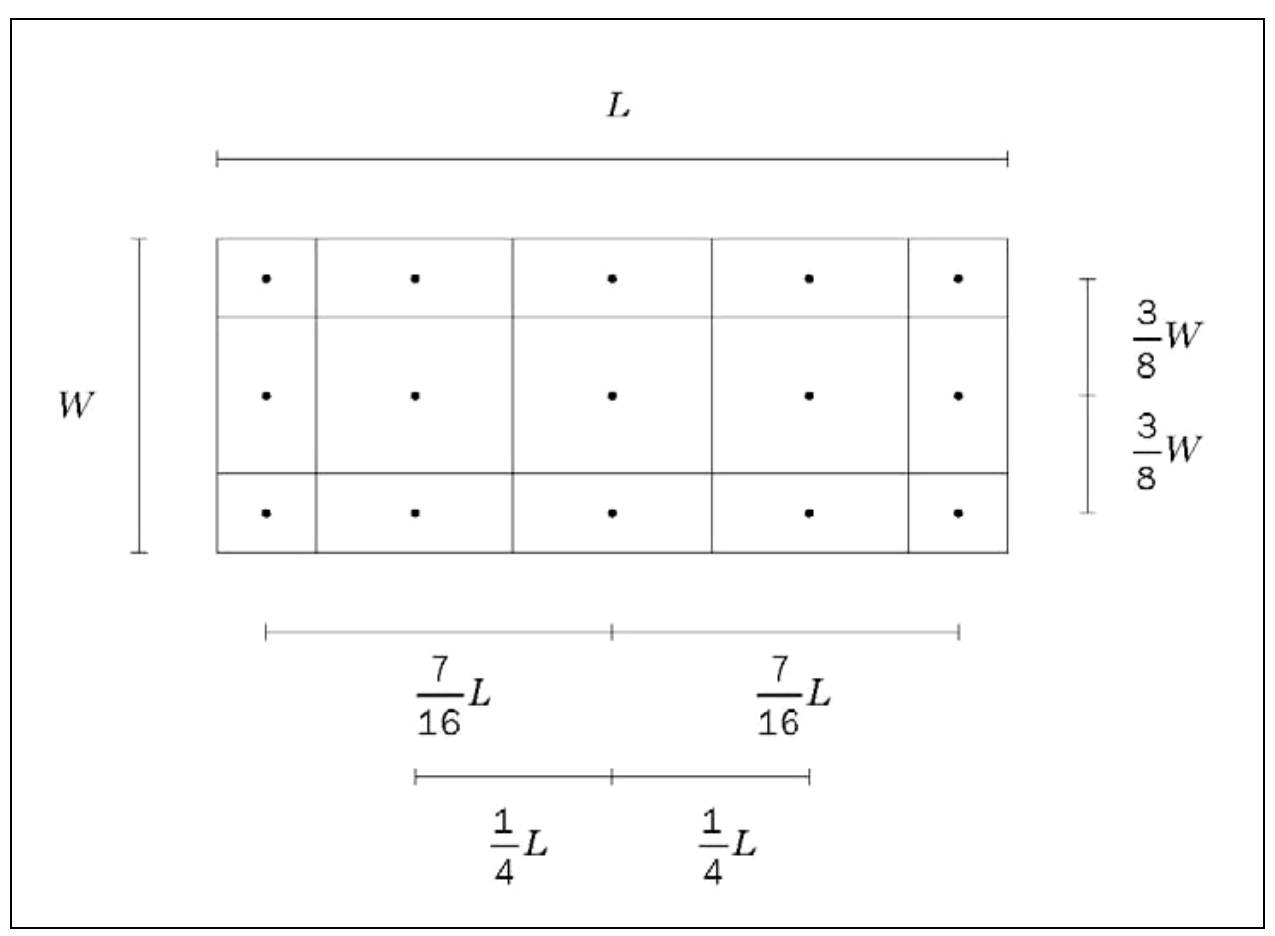

Figure 9. Distribution of points used to calculate the vessel pressure head. 
The ambient flow velocity is required to calculate the vessel velocity relative to the flow, which, in turn, is used in the shear stress relations described below. This ambient velocity is calculated as the flow velocity at a point located three-fourths of a vessel length in front of the vessel. The velocity at this location, relative to the vessel, is interpolated each time step. Care should be taken during mesh construction to ensure that this interpolation point never falls outside the mesh. That is, the front of the vessel should not come within three-fourths of a vessel length from the edge of the mesh. Figure 10 schematically shows the point used to calculate the ambient flow velocity and its location relative to the vessel.

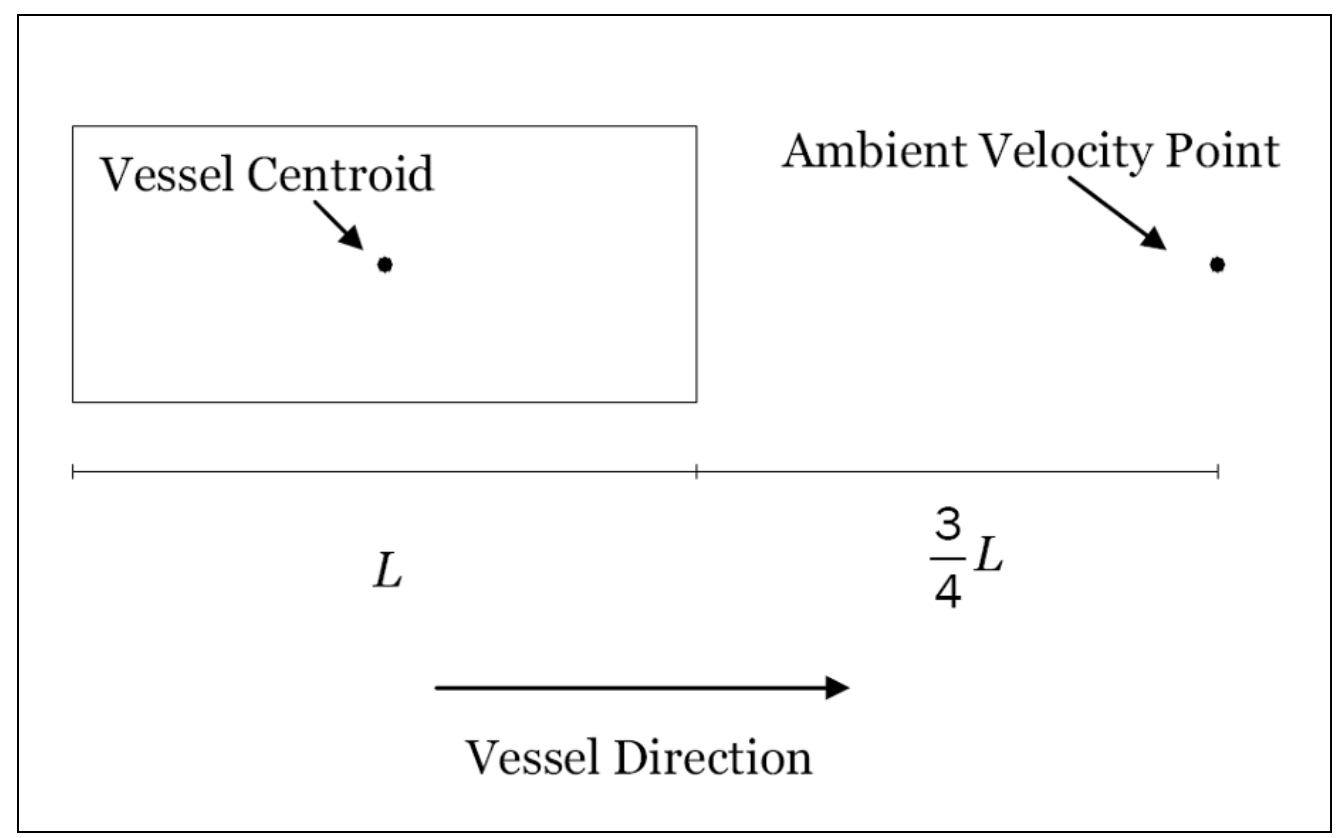

Figure 10. Location of ambient velocity calculation point relative to the vessel.

\section{Limitations of the shear stress relations}

The vessel-induced bed shear stresses routines are only valid for barge tows and towboats, as there are currently no data to formulate vesselgenerated bed shear stress routines for ships. Also, the shear stress relations must be expressed in SI units. The stress relations described in this report give stresses in units of dynes $/ \mathrm{cm}^{2}$.

The trail representing the decay of bed shear stress induced by the propeller is always aligned with the vessel. This alignment becomes an issue with curved sections of sailing lines such as when a vessel navigates a bend. 


\section{Defining the propeller in ADH}

An OP BTS card ${ }^{1}$ must be added to the boundary condition file, and a PROP card added to the boat definition file when modeling a vessel. Also, the pertinent propeller information must be added to the boat file. A description of each parameter that must be included with the PROP card is given in Appendix C. The towboat length is also included in the PROP card. This length provides an offset distance of the propeller induced shear stresses from the vessel.

\section{Stress output}

The stress values are output to an American Standard Code for Information Interchange (ASCII) data file that can be read directly into an XMS application such as SMS or GMS. ${ }^{2}$ This file can be opened in SMS to show shear stress contours just as velocity magnitude or depth contours are generated from velocity (*_ovl.dat) and depth (*_dep.dat) files. The naming convention for the near-field vessel-induced shear stress file in $\mathrm{ADH}$ is to append “_str.dat” to the job name.

Bed shear stresses attributed to the flow field, including the return currents, can be computed using the velocity solution. These stresses can be calculated in SMS (with the data calculator) using:

$$
\tau_{f}=\frac{1}{2} \rho C V_{f}^{2}
$$

where:

$$
\begin{aligned}
\tau_{f} & =\text { bed shear stress due to ambient and return currents } \\
C & =\text { coefficient of friction for the bed (taken as } 0.01 \text { for a sand bed) } \\
V_{f} & =\text { flow velocity magnitude (ambient). }
\end{aligned}
$$

\footnotetext{
1 "Card" refers to the set of characters that begin a line in an ADH input file. In this case, the line in the input file would begin with "OP BTS."

2 SMS and GMS are two software packages used by the U.S. Army Corps of Engineers to generate 2D (SMS) and 3D (GMS) grids as well as perform data analyses and other post-processing.
} 


\section{Modeling Bed Shear Stress}

\section{Introduction}

The vessel-induced bed shear stresses are important because sediment suspension and transport is determined by the shear stress acting on the bed. For a sediment particle to be suspended and transported within the flow, the shear stress acting on the particle must be higher than a critical shear stress value. The shear stress induced on the bed by a passing vessel is a large portion of the total bed shear stress, so calculating the vessel induced bed shear stress is an important in determining sediment transport patterns.

\section{Model setup}

The bed shear stresses induced by the W.C. Norman sailing on the Illinois Waterway at Kampsville, IL, were calculated. Chapter 2 describes the details of the vessel and the channel.

\section{Shear stress results}

Figure 11 shows a longitudinal distribution of the bow-, propeller-, and flow-field-induced bed shear stress at an instance in time during a simulation. These shear stresses are normalized by the peak bow-induced shear stress, and the $\mathrm{x}$-axis shows the relative position of the vessel with 0.5 corresponding to the bow and -0.5 corresponding to the stern. The peak bow shear stress occurs slightly aft of the bow. Laboratory work by Maynord (2000) suggests that the peak bow stress occurs at a point $0.04 \mathrm{~L}$ astern of the bow. The propeller-induced shear stress peaks aft of the vessel's stern immediately behind the towboat. Notice that the flow-fieldinduced shear stresses, seen in the regions greater than half a vessel length in front of the vessel and two vessel lengths behind the barge train, are at least an order of magnitude smaller than those induced by the vessel. Therefore, the flow-field-induced bed shear stresses can be ignored when only the peak shear stress values are of interest. 


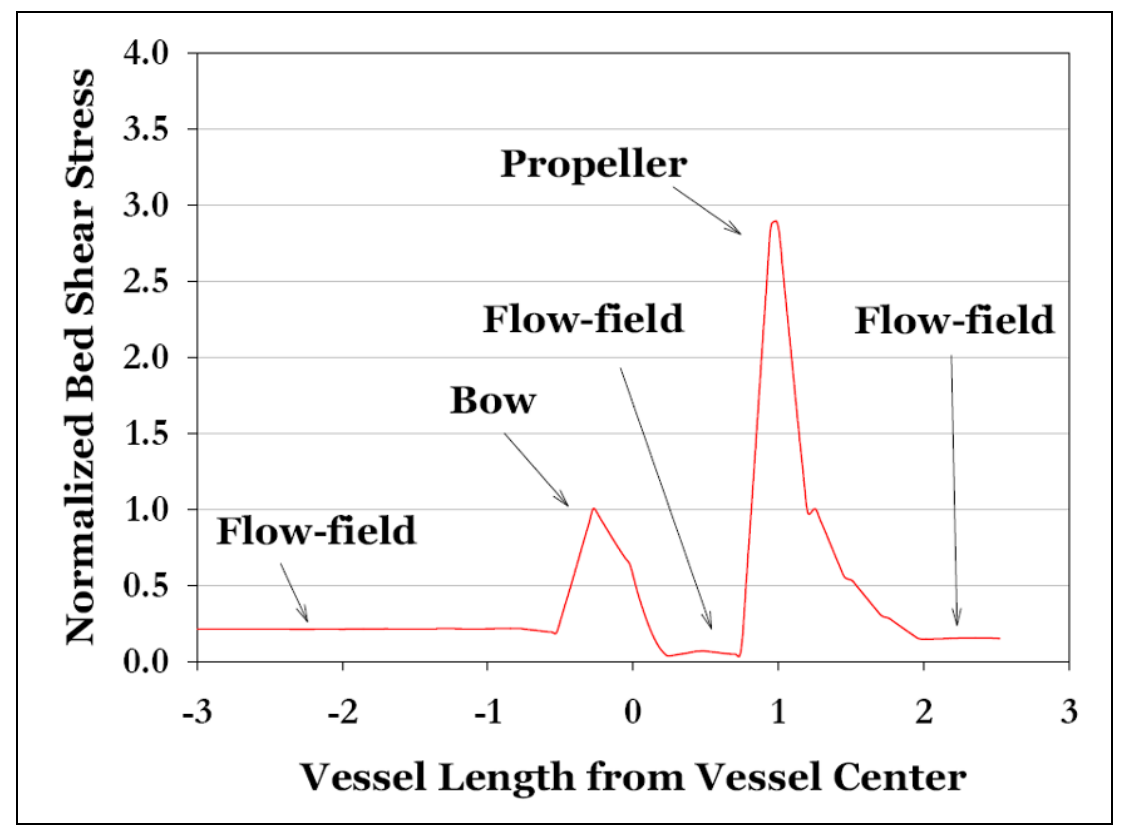

Figure 11. Longitudinal shear stress plot in the vessel vicinity along the sailing line.

Figure 12 shows the vessel-induced bed shear stress contours at an instant in time as the vessel is moving from right to left through the channel. The white rectangle represents the vessel outline. The contours show that the bow- and propeller-induced bed shear stresses are localized around the vessel. The propeller-induced stress is much larger than that of the bow. The contours show that the propeller-induced bed shear stresses decay but remain aligned with the vessel. The stress contours are not symmetric with respect to the centerline of the vessel because the mesh is not symmetrical.

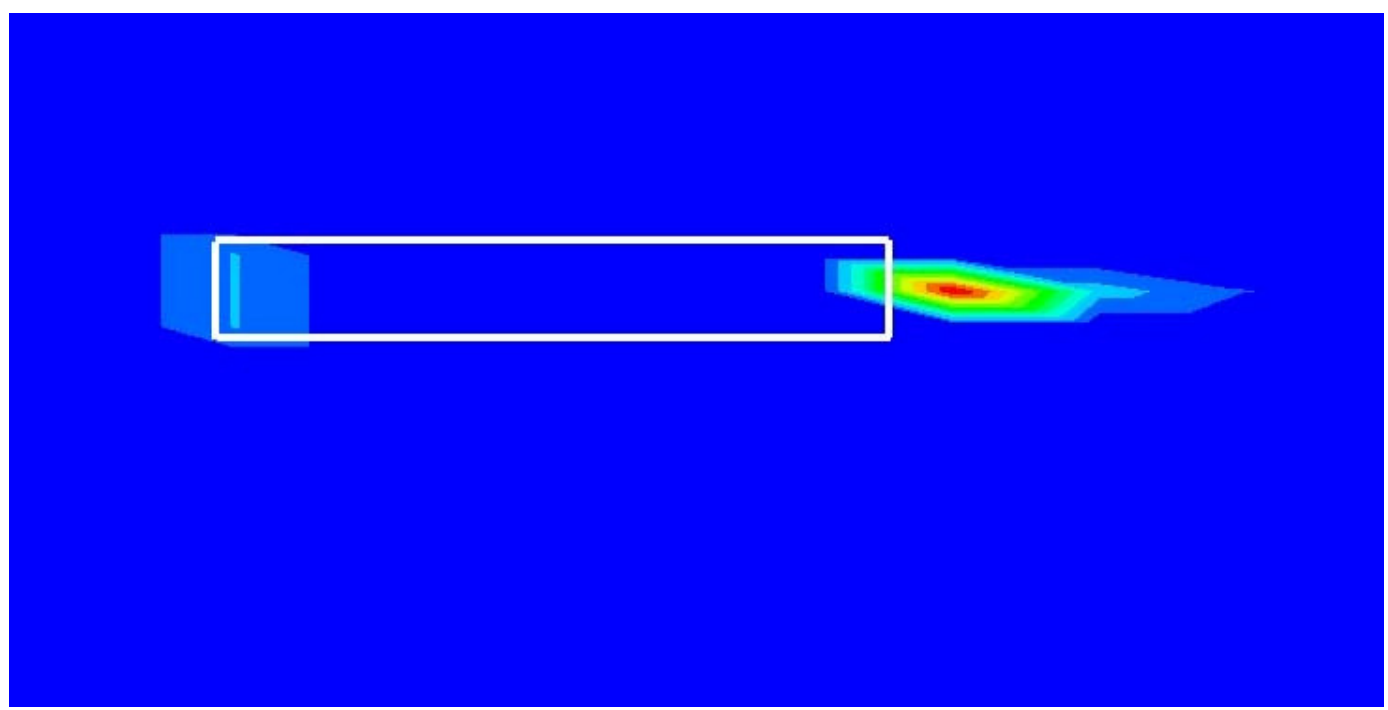

Figure 12. Shear stress contours and their location relative to the vessel. 


\section{Summary, Conclusions, and Recommendations}

\section{Summary}

Vessel entrainment relations have been added to the $2 \mathrm{D}$, shallow-water module of the hydrodynamic finite-element code, $\mathrm{ADH}$. These relations allow the user to calculate low-frequency, vessel-induced waves within a flow field for a vessel moving along a pre-defined sailing path. The required setup- and run-time has been reduced from that required by other models because of the adaptive meshing capabilities within ADH. Guidelines have been developed for generating an initial mesh near a vessel's sailing path, and suggested values for ADH mesh refinement parameters have been determined. A test case was run to compare the calculated flow field to existing field data. Histories of the calculated longitudinal and transverse velocities compare well with field data.

The capability to model bow- and propeller-induced bed shear stresses attributed to barge tows has been added to $\mathrm{ADH}$. The relations used to describe the shear stresses acting on the bed are empirical based on the work reported by Maynord (2000). These relations have been generalized so that a single set of equations defines both upbound and downbound vessel movement. Example plots of shear stress distributions near the vessel are given. These relations show the relative strength that the bow and the propeller have in inducing bed shear stresses.

\section{Conclusions}

Guidance was developed for setting up a vessel simulation using ADH. The elements near the vessel should be approximately one-half of the vesselwidth wide and one-third of the vessel-length long. This ensures that two elements fall laterally and three elements fall longitudinally within the vessel footprint. The mesh refinement tolerance should be set to a representative value of the residual at nodes in the region of the mesh far from the vessel. Two levels of refinement are appropriate. The propellerinduced peak shear stress is several orders of magnitude larger than that at the bow. 


\section{Recommendations for future work}

The shear stress relations are valid for specific types of vessels and flow conditions. A laboratory study should be directed at determining more general relations applicable to a wider variety of vessels. These studies should include additional analyses of the propeller jet, which has been shown to induce the largest bed shear stress. 


\section{References}

Berger, C., and L. Lee. 2005. Modeling of vessel effects: Selection of adaption parameters for modeling vessels in ADH. ERDC/CHL CHETN-IX-15. Vicksburg, MS: U.S. Army Engineer Research and Development Center.

Bhowmik, N. G., T. W. Soong, and R. Xia. 1993. Physical effects of barge tows on the Upper Mississippi River System: Analysis of existing data collected by the Illinois Water Survey from the Kampsville Site on the Illinois River. Draft Progress Report No. 2. Champaign, IL: Illinois State Water Survey.

Garcia, M. H., D. M. Admiraal, J. Rodriguez, and F. Lopez. 2002. Navigation-induced bed shear stresses: Laboratory measurements, data analysis, and application. Civil Engineering Studies, Hydraulic Engineering Series No. 56. University of Illinois at Urbana-Champaign.

Maynord, S. T. 2000. Physical forces near commercial tows. ENV Report 19. Vicksburg, MS: U.S. Army Engineer Research and Development Center. 2003. Ship effects before and after deepening of Sabine-Neches Waterway, Port Author, Texas. ERDC/CHL TR-03-15. Vicksburg, MS: U.S. Army Engineer Research and Development Center.

Stockstill, R. L., and R. C. Berger. 1999. A two-dimensional flow model for vesselgenerated currents. ENV Report 10. Vicksburg, MS: U.S. Army Engineer Research and Development Center. . 2001. Simulating barge drawdown and currents in channel and backwater areas. Journal of Waterway, Port, Coastal, and Ocean Engineering 127(5):290298.

Stockstill, R. L., S. C. Martin, and R. C. Berger. 1995. Hydrodynamic model of vesselgenerated currents. Regulated Rivers: Research and Management 11:211-225.

Toutant, W. T. 1982. Mathematical performance models for river tows. Proc., Winter Meeting, Great Lakes and Great Rivers Sections. Clarksville, IN: The Society of Naval Architects and Marine Engineers. 


\section{Appendix A: Shallow-Water Equations}

The shallow-water (or long-wave) equations are a result of the vertical integration of the equations of mass and momentum conservation for incompressible flow under a hydrostatic pressure assumption. The flow depth $(h)$, the depth-averaged $x$-component of velocity $(u)$, and the depthaveraged $y$-component of velocity $(v)$ define the dependent variables of the fluid motion. If the fluid pressure at the surface is taken as zero and the free-surface stresses are neglected, the shallow-water equations are given as:

$$
\frac{\partial U}{\partial t}+\frac{\partial F}{\partial x}+\frac{\partial G}{\partial y}+H=0
$$

where:

$$
\begin{gathered}
U=\left\{\begin{array}{c}
h \\
u h \\
v h
\end{array}\right] \\
F=\left\{\begin{array}{c}
u h \\
u^{2} h+\frac{1}{2} g h^{2}-h \frac{\sigma_{x x}}{\rho} \\
u v h-h \frac{\sigma_{y x}}{\rho}
\end{array}\right\} \\
G=\left\{\begin{array}{c}
v h \\
u v h-h \frac{\sigma_{y x}}{\rho} \\
v h^{2}+\frac{1}{2} g h^{2}-h \frac{\sigma_{y y}}{\rho}
\end{array}\right\}
\end{gathered}
$$


and

$$
H=\left\{\begin{array}{c}
0 \\
g h \frac{\partial z_{b}}{\partial x}+\frac{h}{\rho} \frac{\partial P}{\partial x}+n^{2} g \frac{u \sqrt{u^{2}+v^{2}}}{h^{1 / 3}} \\
g h \frac{\partial z_{b}}{\partial y}+\frac{h}{\rho} \frac{\partial P}{\partial y}+n^{2} g \frac{v \sqrt{u^{2}+v^{2}}}{h^{1 / 3}}
\end{array}\right\}
$$

where:

$$
\begin{aligned}
\rho & =\text { fluid density } \\
g & =\text { acceleration due to gravity } \\
z_{b} & =\text { bed elevation } \\
n & =\text { Manning's roughness coefficient } \\
P & =\text { pressure head. }
\end{aligned}
$$

The o's represent the Reynolds stresses due to turbulence acting on a unit particle of the fluid. The first subscript indicates the direction of the stress, and the second indicates the face of the unit particle on which the stress acts. Using the Bousinesq approach, the Reynolds stresses are:

$$
\begin{aligned}
& \sigma_{x x}=2 \rho v_{t} \frac{\partial u}{\partial x} \\
& \sigma_{y y}=2 \rho v_{t} \frac{\partial v}{\partial y}
\end{aligned}
$$

and

$$
\sigma_{x y}=\sigma_{y x}=\rho v_{t}\left(\frac{\partial u}{\partial x}+\frac{\partial v}{\partial y}\right)
$$

where:

$$
v_{t}=\text { kinematic eddy viscosity. }
$$


The eddy viscosity $\left(v_{t}\right)$ can be determined from:

$$
v_{t}=B h V \sqrt{f}
$$

where:

$$
\begin{aligned}
& B=\text { empirical constant that falls between } 0.1 \text { and } 1.0 \\
& V=\text { magnitude of the flow velocity } \\
& f=\text { Darcy friction factor. }
\end{aligned}
$$




\section{Appendix B: Mesh Convergence}

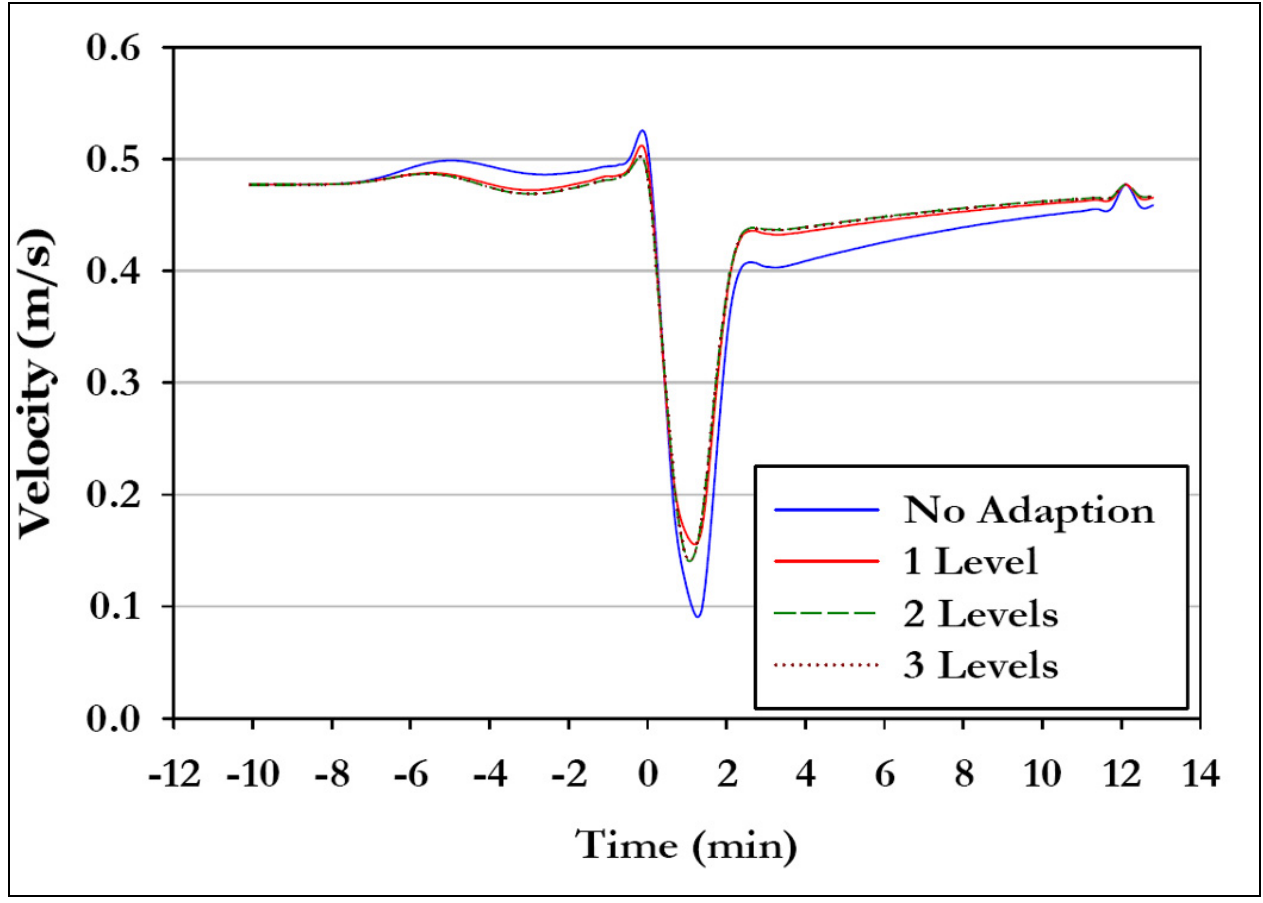

Figure B1. Mesh refinement results, longitudinal component of velocity at Gauge 040.

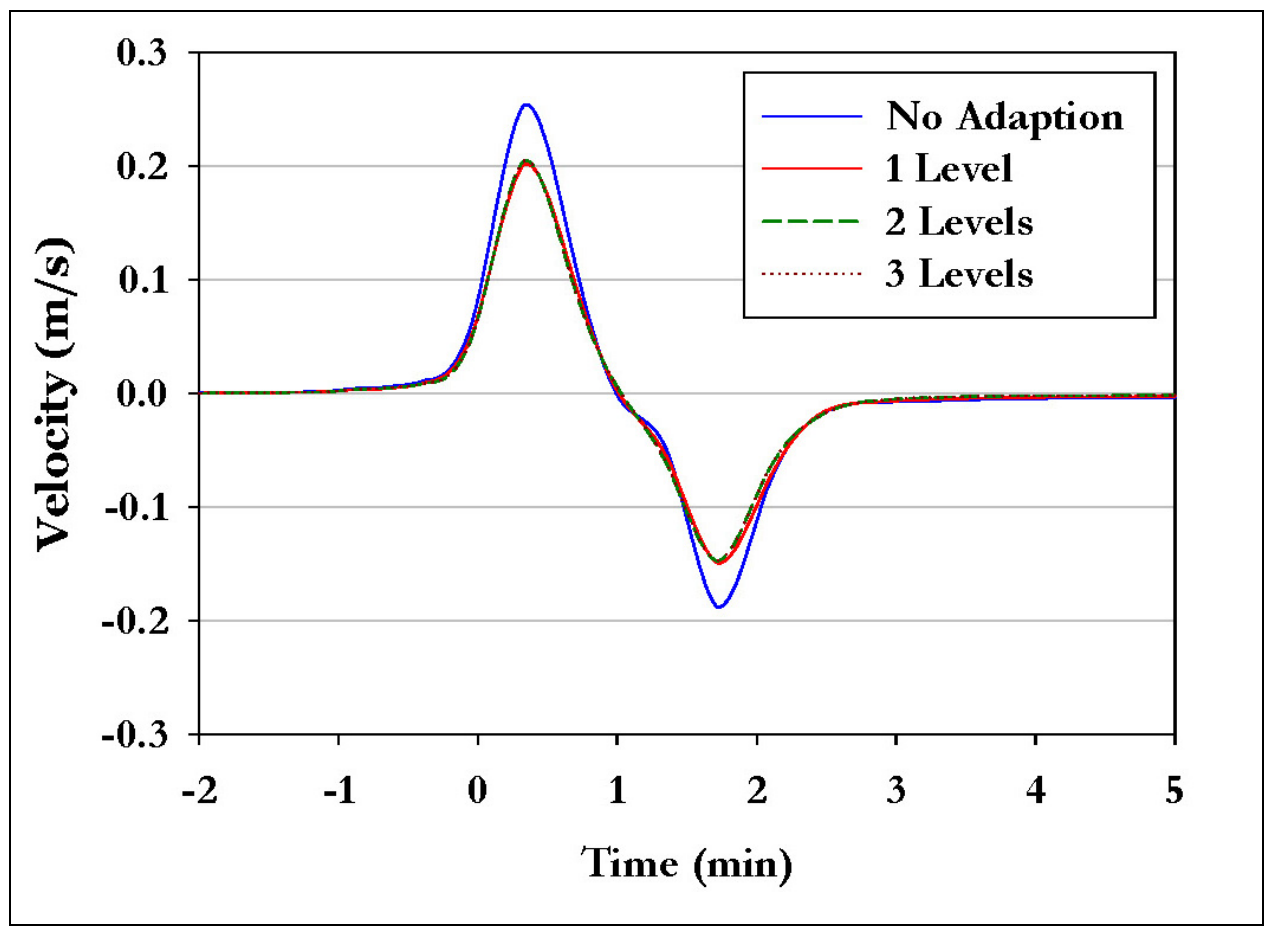

Figure B2. Mesh refinement results, transverse component of velocity at Gauge 040. 


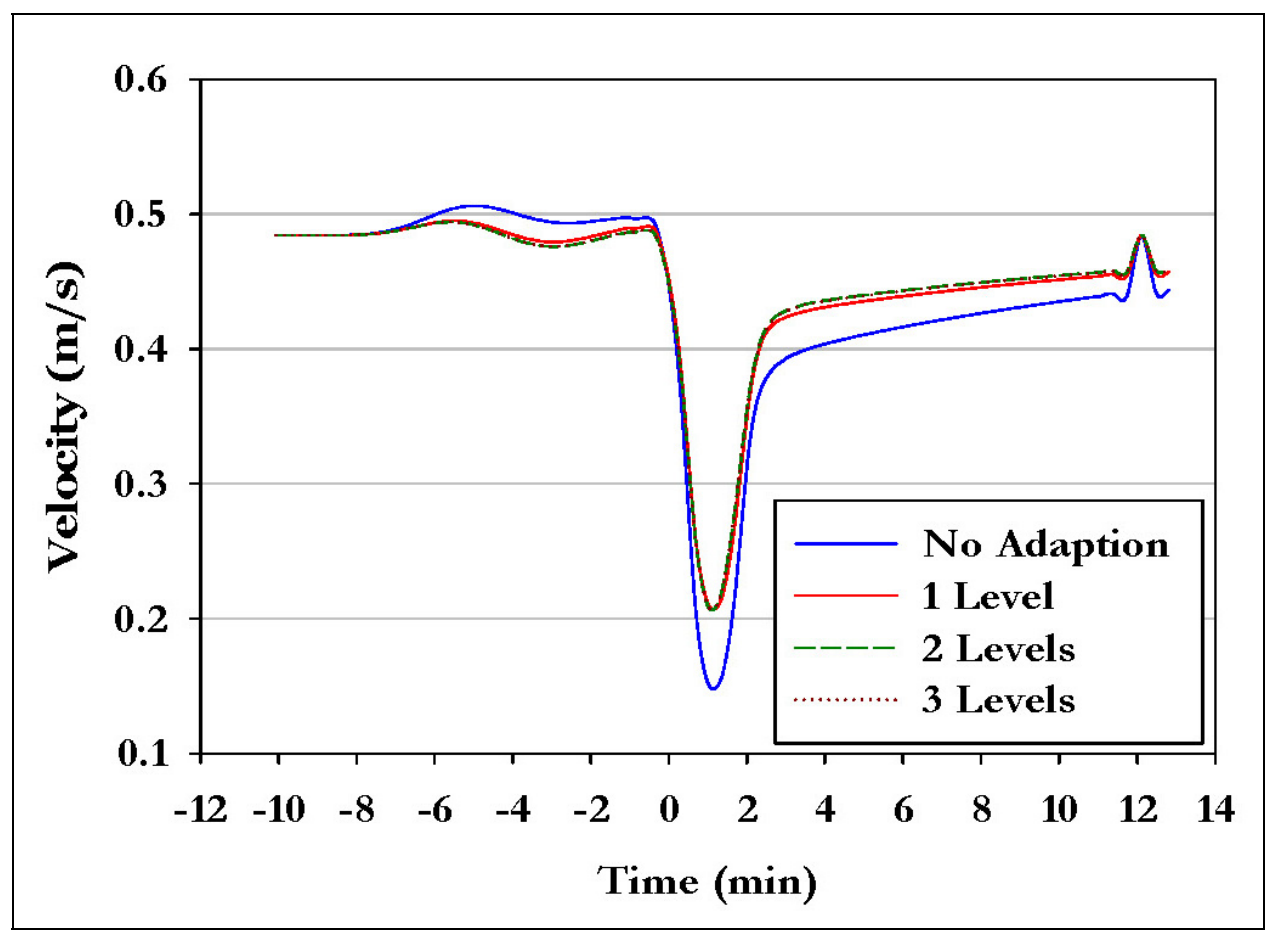

Figure B3. Mesh refinement results, longitudinal component of velocity at Gauge 071.

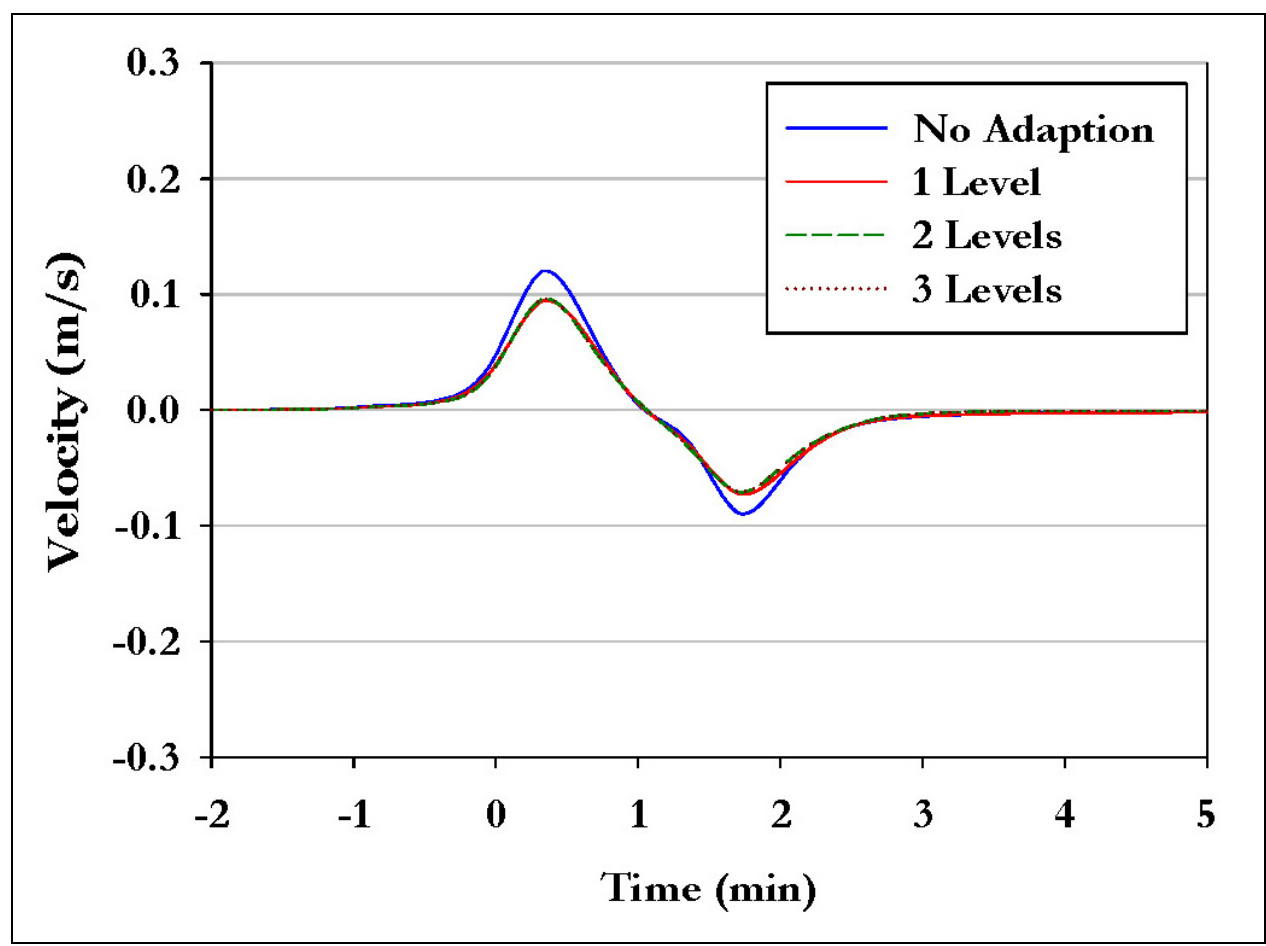

Figure B4. Mesh refinement results, transverse component of velocity at Gauge 071. 


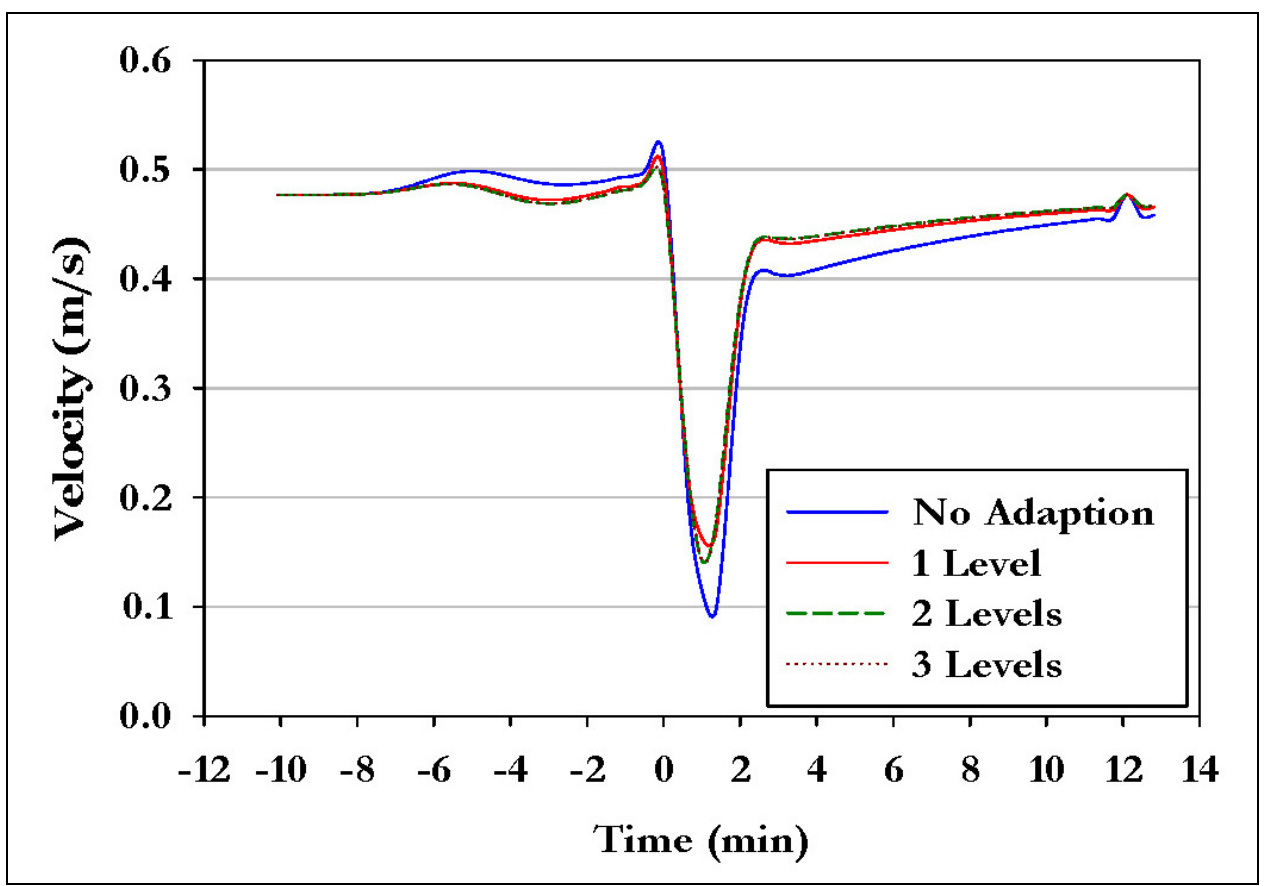

Figure B5. Mesh refinement results, longitudinal component of velocity at Gauge 332.

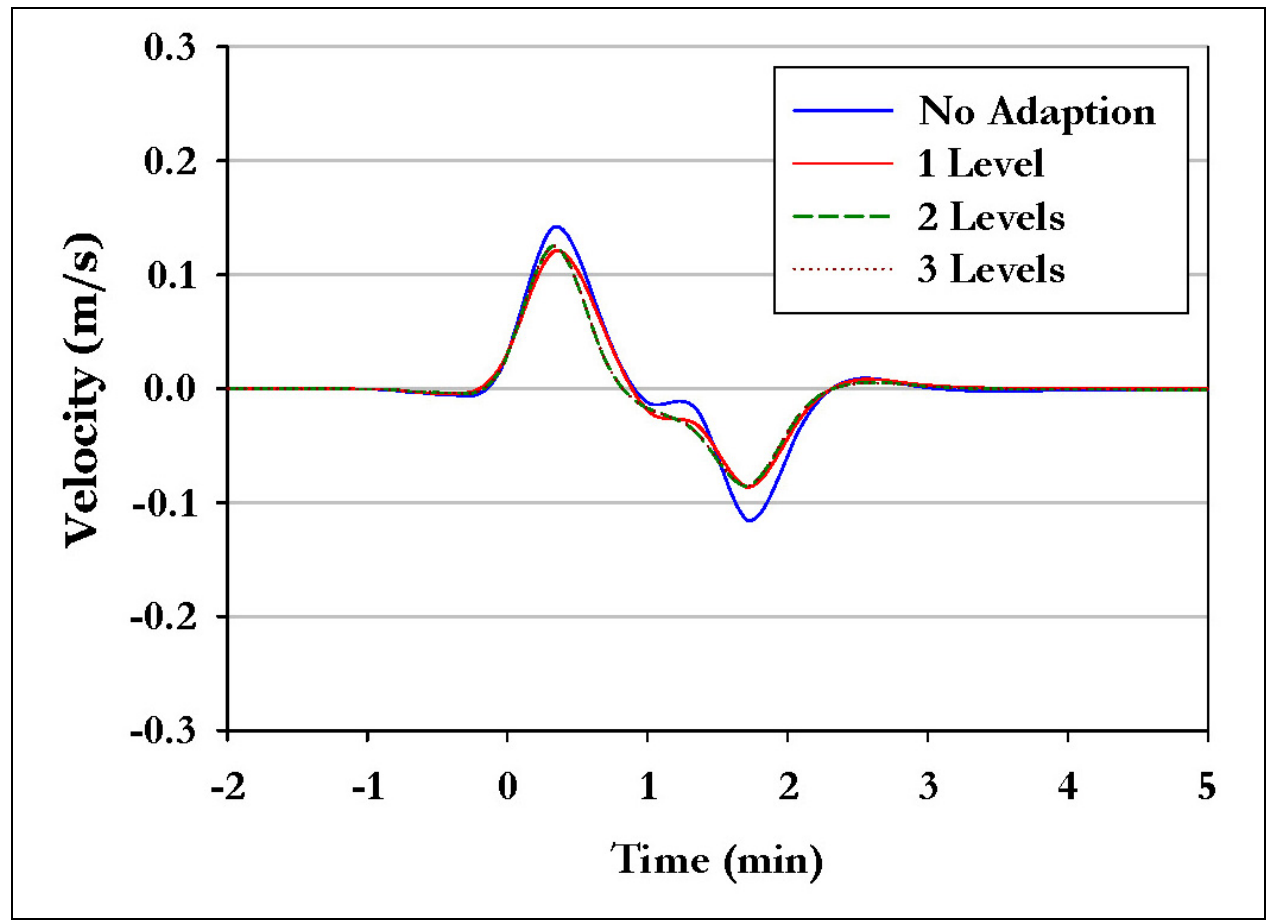

Figure B6. Mesh refinement results, transverse component of velocity at Gauge 332. 


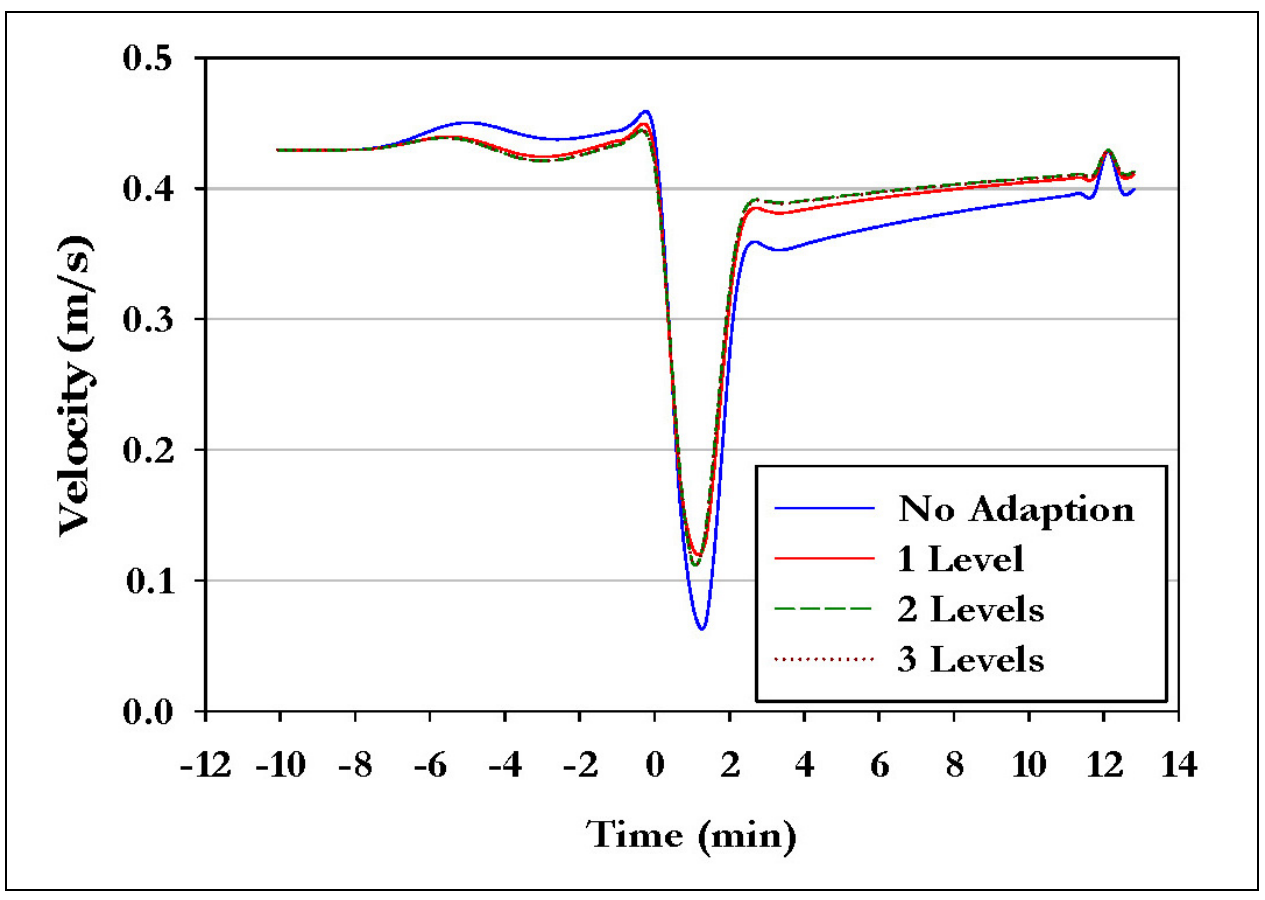

Figure B7. Mesh refinement results, longitudinal component of velocity at Gauge 642 .

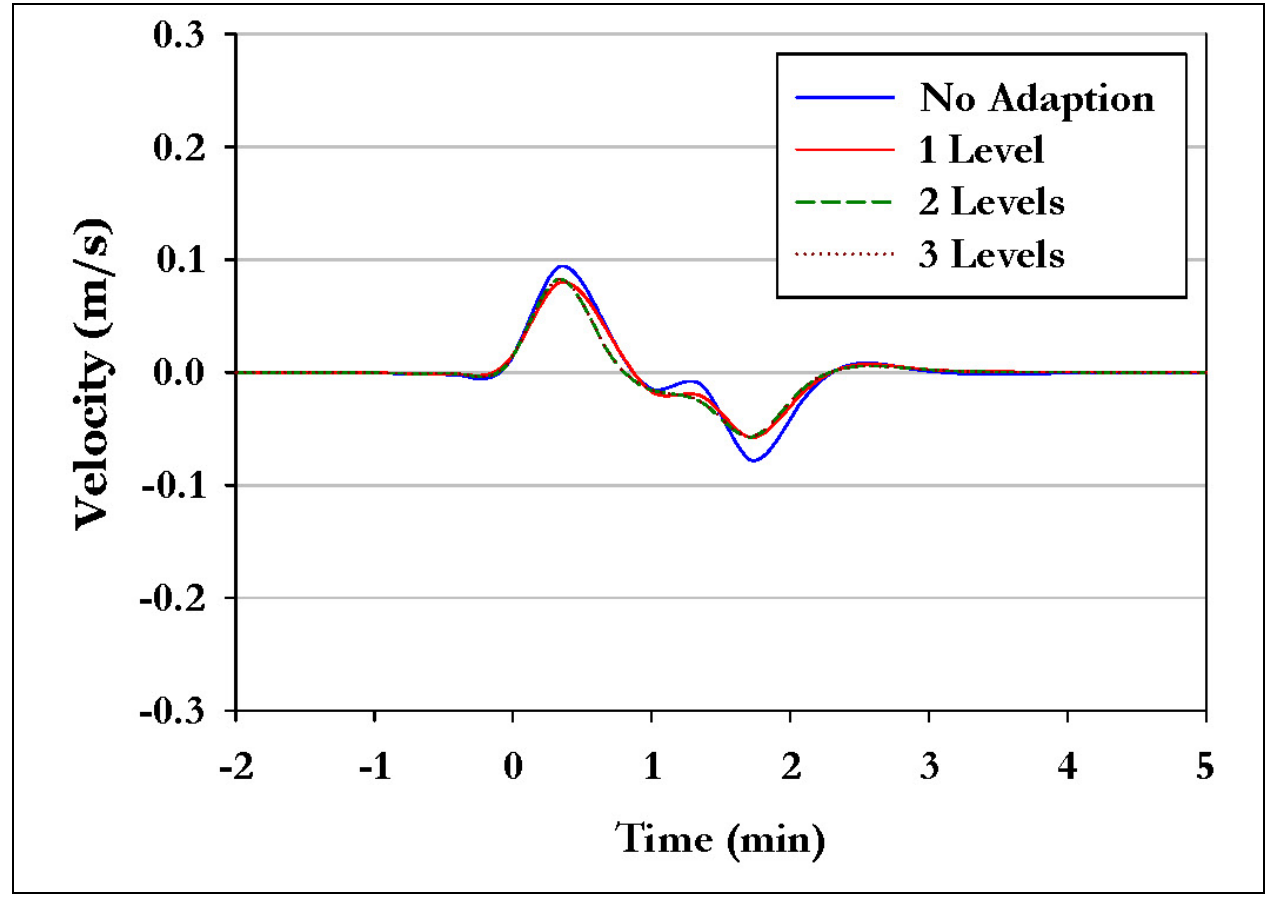

Figure B8. Mesh refinement results, transverse component of velocity at Gauge 642. 


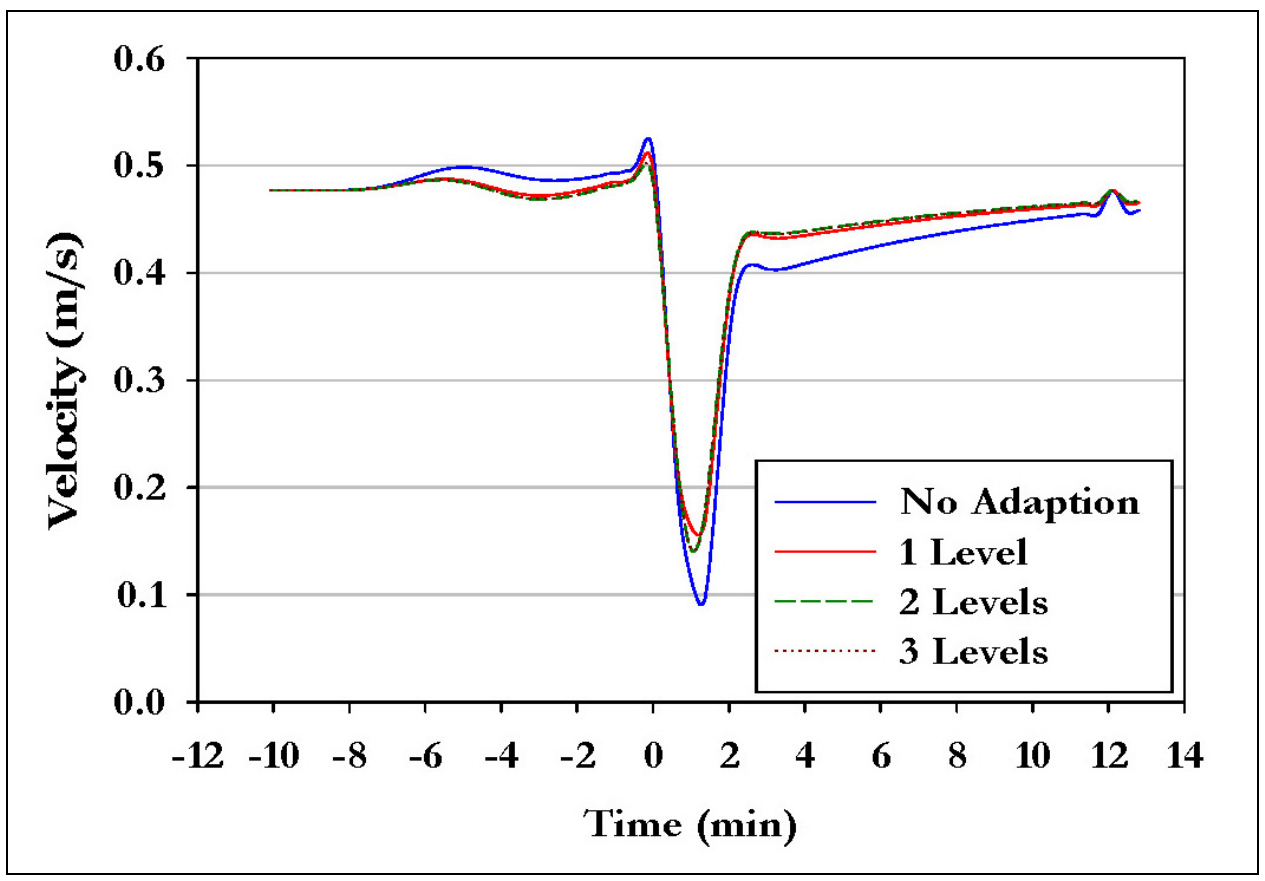

Figure B9. Mesh refinement results, longitudinal component of velocity at Gauge 999.

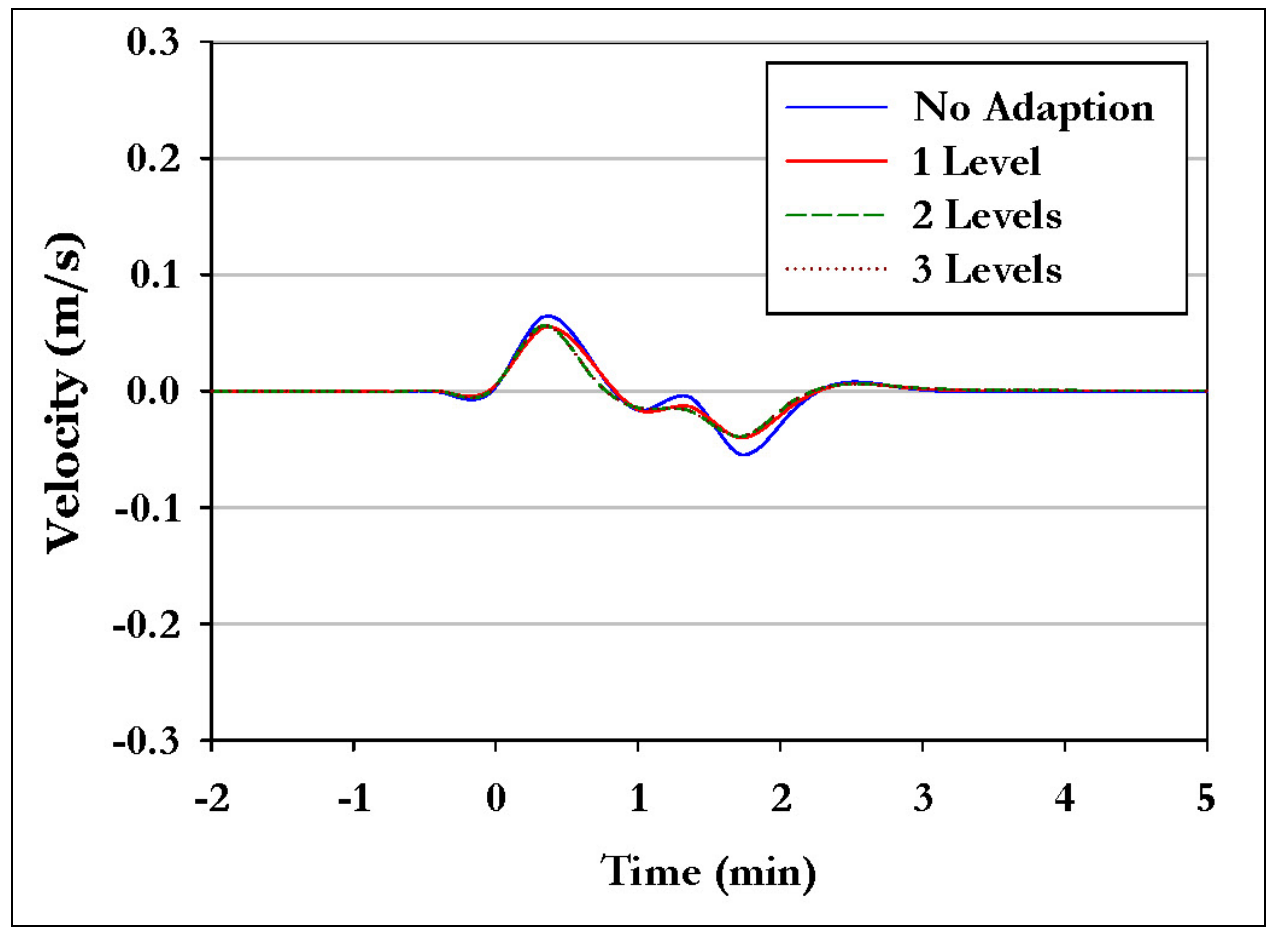

Figure B10. Mesh refinement results, transverse component of velocity at Gauge 999. 


\section{Appendix C: Boat File Description}

The boat file card and field descriptions given below in Tables $\mathrm{C}_{1}-\mathrm{C}_{5}$ are current as of July 2007. These cards are subject to future modifications as the $\mathrm{ADH}$ vessel entrainment model is extended. Current boat file card and field descriptions can be found at http://adh.usace.army.mil/ under the "Manuals" (last bulleted item): "Quick Reference (Carrillo and Hallberg 2005)."

Table C1. Number of vessels.

\begin{tabular}{|l|l|l|l|}
\hline Field & Type & Value & Description \\
\hline 1 & Character & BOAT & Card type \\
\hline 2 & Integer & $>0$ & Number of vessels to be modeled \\
\hline
\end{tabular}

Table C2. Sailing line and initial vessel position.

\begin{tabular}{|l|l|l|l|}
\hline Field & Type & Value & Description \\
\hline 1 & Character & FDEF & Card type \\
\hline 2 & Integer & $>0$ & Vessel number sailing line being defined \\
\hline 3 & Integer & $>0$ & Number of segments in sailing line \\
\hline 4 & Real number & $\#$ & x-coordinate of the vessel's initial position \\
\hline 5 & Real number & $\#$ & -coordinate of the vessel's initial position \\
\hline 6 & Real number & $\#$ & Initial velocity magnitude of the vessel \\
\hline
\end{tabular}

Table C3. Vessel draft.

\begin{tabular}{|l|l|l|l|}
\hline Field & Type & Value & Description \\
\hline 1 & Character & DRFT & Card type \\
\hline 2 & Integer & $>0$ & Vessel number \\
\hline 3 & Real number & $>0$ & Vessel draft \\
\hline
\end{tabular}

Table C4. Vessel length.

\begin{tabular}{|l|l|l|l|}
\hline Field & Type & Value & Description \\
\hline 1 & Character & BLEN & Card type \\
\hline 2 & Integer & $>0$ & Vessel number \\
\hline 3 & Real number & $>0$ & Vessel length \\
\hline
\end{tabular}


Table C5. Vessel width.

\begin{tabular}{|l|l|l|l|}
\hline Field & Type & Value & Description \\
\hline 1 & Character & BWID & Card type \\
\hline 2 & Integer & $>0$ & Vessel number \\
\hline 3 & Real number & $>0$ & Vessel width \\
\hline
\end{tabular}

Table C6. Bow-to-length ratio.

\begin{tabular}{|l|l|l|l|}
\hline Field & Type & Value & Description \\
\hline 1 & Character & PBOW & Card type \\
\hline 2 & Integer & $>0$ & Vessel number \\
\hline 3 & Real number & $>0$ & Ratio of the bow length to the vessel length \\
\hline
\end{tabular}

Table C7. Stern-to-length ratio.

\begin{tabular}{|l|l|l|l|}
\hline Field & Type & Value & Description \\
\hline 1 & Character & PSTR & Card type \\
\hline 2 & Integer & $>0$ & Vessel number \\
\hline 3 & Real number & $>0$ & Ratio of the stern length to the vessel length \\
\hline
\end{tabular}

Table C8. Fraction of draft applied to PBOW.

\begin{tabular}{|l|l|l|l|}
\hline Field & Type & Value & Description \\
\hline 1 & Character & CBOW & Card type \\
\hline 2 & Integer & $>0$ & Vessel number \\
\hline 3 & Real number & $>0$ & Bow draft ratio \\
\hline
\end{tabular}

Table C9. Fraction of draft applied to PSTR.

\begin{tabular}{|l|l|l|l|}
\hline Field & Type & Value & Description \\
\hline 1 & Character & CSTR & Card type \\
\hline 2 & Integer & $>0$ & Vessel number \\
\hline 3 & Real number & $>0$ & Stern draft ratio \\
\hline
\end{tabular}

Previous studies have concluded that the flow solution is not very sensitive to the ratios described in Tables $\mathrm{C6}-\mathrm{C} 9$. A reasonable value for $\mathrm{PBOW}$ and PSTR is 0.1, and 0.95 is appropriate for CBOW and CSTR. 
Table C10. Sailing-line segment definition.

\begin{tabular}{|l|l|l|l|}
\hline Field & Type & Value & Description \\
\hline 1 & Character & SDEF & Card type \\
\hline 2 & Integer & $>0$ & Vessel number \\
\hline 3 & Integer & $>0$ & Sailing line segment number \\
\hline 4 & Integer & 0 or 1 & Type of segment; $(0$ for line; 1 for arc $)$ \\
\hline 5 & Real number & $\#$ & x-coordinate of the segment end \\
\hline 6 & Real number & $\#$ & y-coordinate of segment end \\
\hline 7 & Real number & $\#$ & Vessel velocity at the segment end \\
\hline 8 & Real number & $\#$ & $\begin{array}{l}\text { If the segment is an arc, the } x \text {-coordinate } \\
\text { of the arc center }\end{array}$ \\
\hline 9 & Real number & $\#$ & $\begin{array}{l}\text { If the segment is an arc, the } y \text {-coordinate } \\
\text { of the arc center }\end{array}$ \\
\hline 10 & Real number & \pm 1.0 & $\begin{array}{l}\text { If the segment is an arc, the direction of } \\
\text { turn }(+1.0 \text { for left turns and }-1.0 \text { for right } \\
\text { turns) }\end{array}$ \\
\hline
\end{tabular}

The vessel velocity is specified at the end of each sailing-line segment. The vessel velocity is varied linearly along each segment of the sailing line.

Table C11. Propeller parameters.

\begin{tabular}{|l|l|l|l|}
\hline Field & Type & Value & Description \\
\hline 1 & Character & PROP & Card type \\
\hline 2 & Integer & $>0$ & Vessel number \\
\hline 3 & Integer & 1 or 2 & Propeller type; (1 for open wheel; 2 for Kort nozzle) \\
\hline 4 & Real number & $>0$ & Propeller diameter \\
\hline 5 & Real number & $>0$ & Distance between centers of the propellers \\
\hline 6 & Real number & $>0$ & Towboat length \\
\hline 7 & Real number & $>0$ & Distance from the propellers to the stern of the towboat \\
\hline
\end{tabular}

Table C12. End of file.

\begin{tabular}{|l|l|l|l|}
\hline Field & Type & Value & Description \\
\hline 1 & Character & ENDD 0 0 & Card type \\
\hline
\end{tabular}




\section{Appendix D: Example with a Complex Sailing Line}

The Kampsville, IL study described in Chapter 2 has a sailing line that is only a single line segment, so the associated boat file does not show how to setup a realistic vessel maneuver. The sailing line, shown in Figure D1, is through Pool 26 of the Mississippi River. This path is more complex, having one line segment and four arcs.

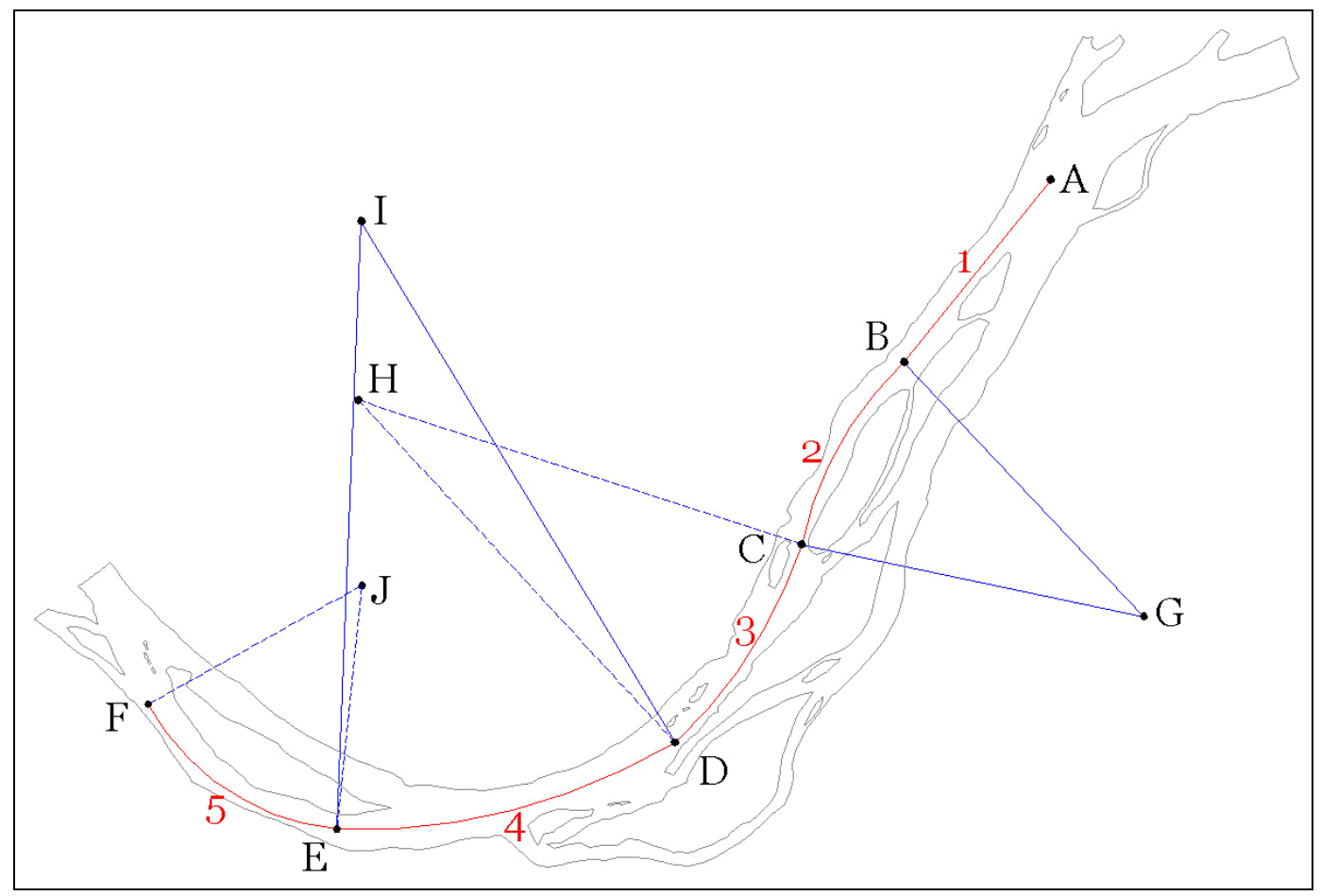

Figure D1. Sailing line and mesh boundaries for Pool 26.

The red lines represent the vessel sailing line and the black lines show the mesh boundaries. The points labeled as letters in Figure D1 are points that must be defined in the boat file. For this sailing line, the vessel is initially at Point A and moves sequentially along the path to Point F. Points G-J are the centers of the four arcs in the sailing line. The coordinates of these points are listed in Table D1. 
Table D1. Sailing line coordinates for Pool 26.

\begin{tabular}{|l|l|l|}
\hline Label & X-coordinate $(\mathrm{m})$ & Y-coordinate $(\mathrm{m})$ \\
\hline A & 718713.764 & 4313644.615 \\
\hline B & 716648.176 & 4311078.278 \\
\hline C & 715208.524 & 4308511.941 \\
\hline D & 713424.606 & 4305726.525 \\
\hline E & 708667.494 & 4304505.950 \\
\hline F & 706007.266 & 4306258.571 \\
\hline G & 720024.618 & 4307497.203 \\
\hline H & 708968.097 & 4310544.656 \\
\hline I & 709007.958 & 4313059.571 \\
\hline J & 709016.860 & 4307931.471 \\
\hline
\end{tabular}

The direction of turn must be specified in the boat file for the four arcs in the sailing line, Segments 2-5. Table D2 lists the direction of turn for each arc in the sailing line as well as the corresponding value that must be placed in the boat file.

Table D2. Direction of turn data for Pool 26.

\begin{tabular}{|l|l|l|}
\hline Segment & Direction of Turn & Boat File Value \\
\hline 2 & Left & 1.0 \\
\hline 3 & Right & -1.0 \\
\hline 4 & Right & -1.0 \\
\hline 5 & Right & -1.0 \\
\hline
\end{tabular}

Figure D1 shows the boat file for this sailing line and vessel, a 3-wide by 5 -long barge tow, drafted at $2.74 \mathrm{~m}$ and traveling at a constant $2.4 \mathrm{~m} / \mathrm{s}$.

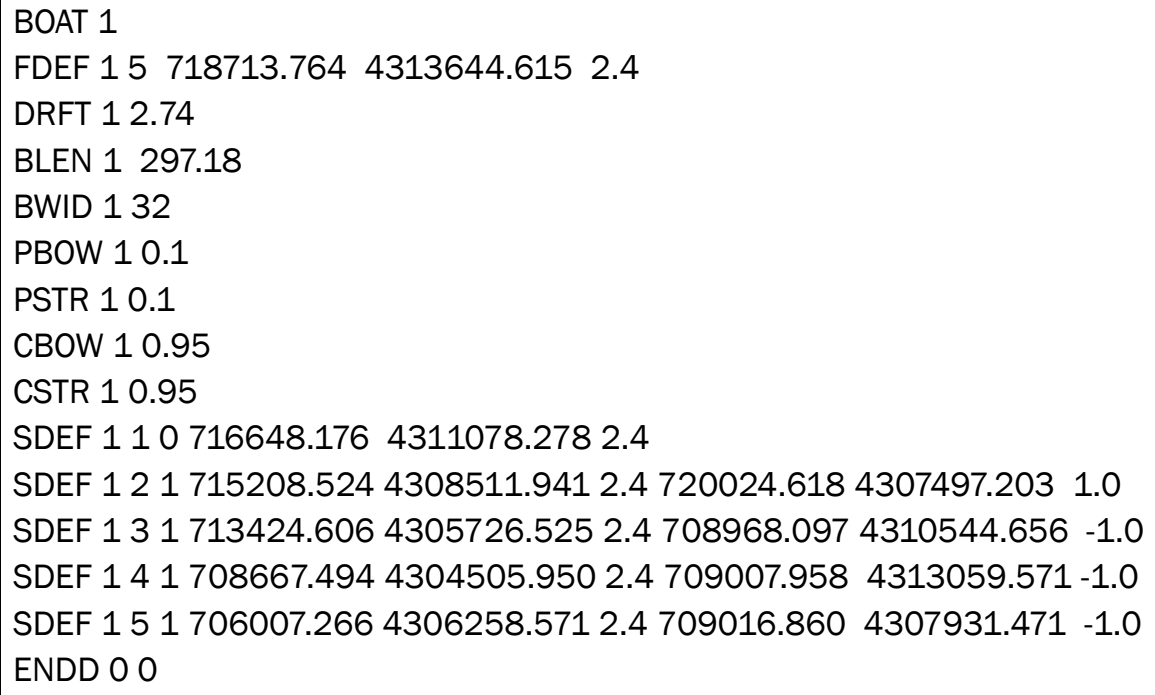

Figure D2. Pool 26 boat file. 


\section{Appendix E: ADH and Field Data Comparison}

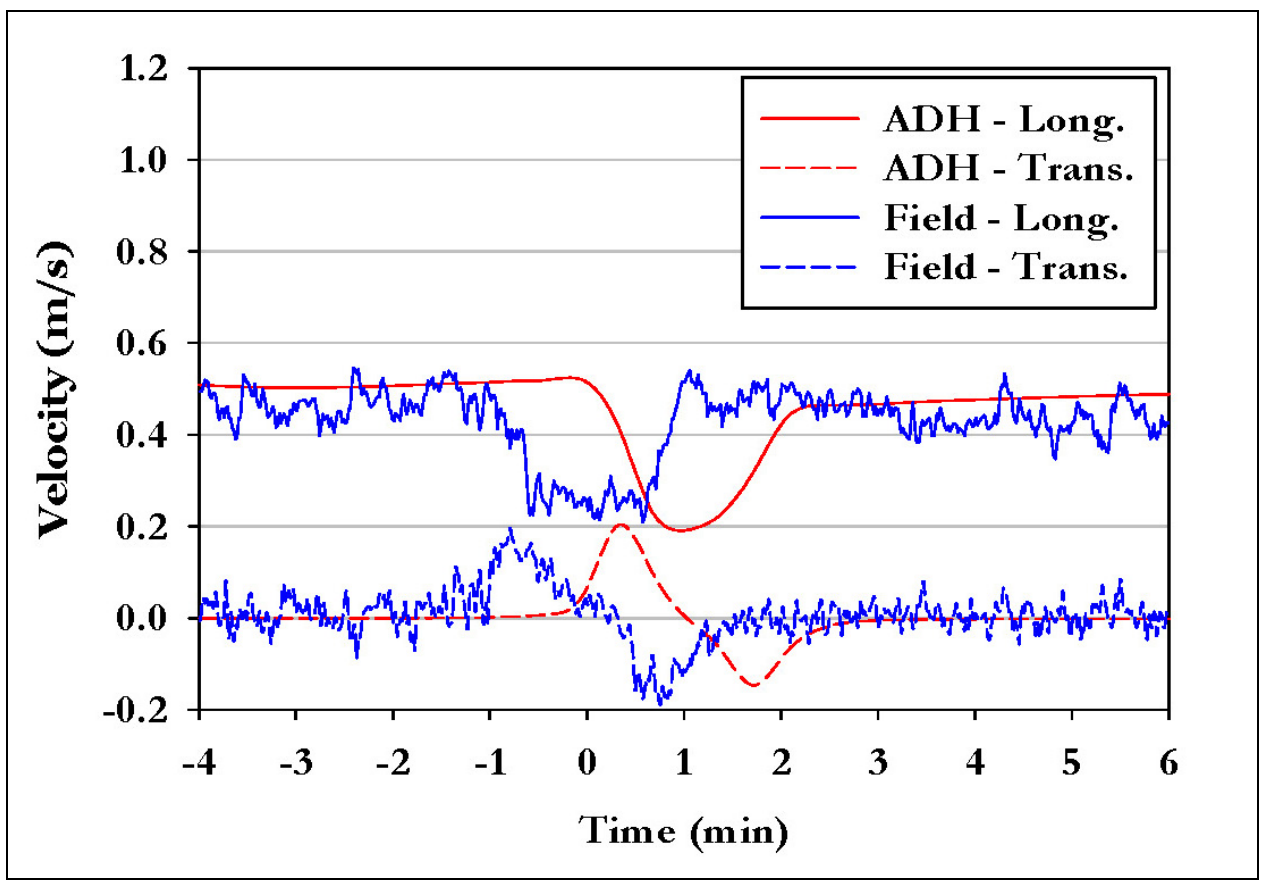

Figure E1. Longitudinal and transverse velocity history, Gauge 040.

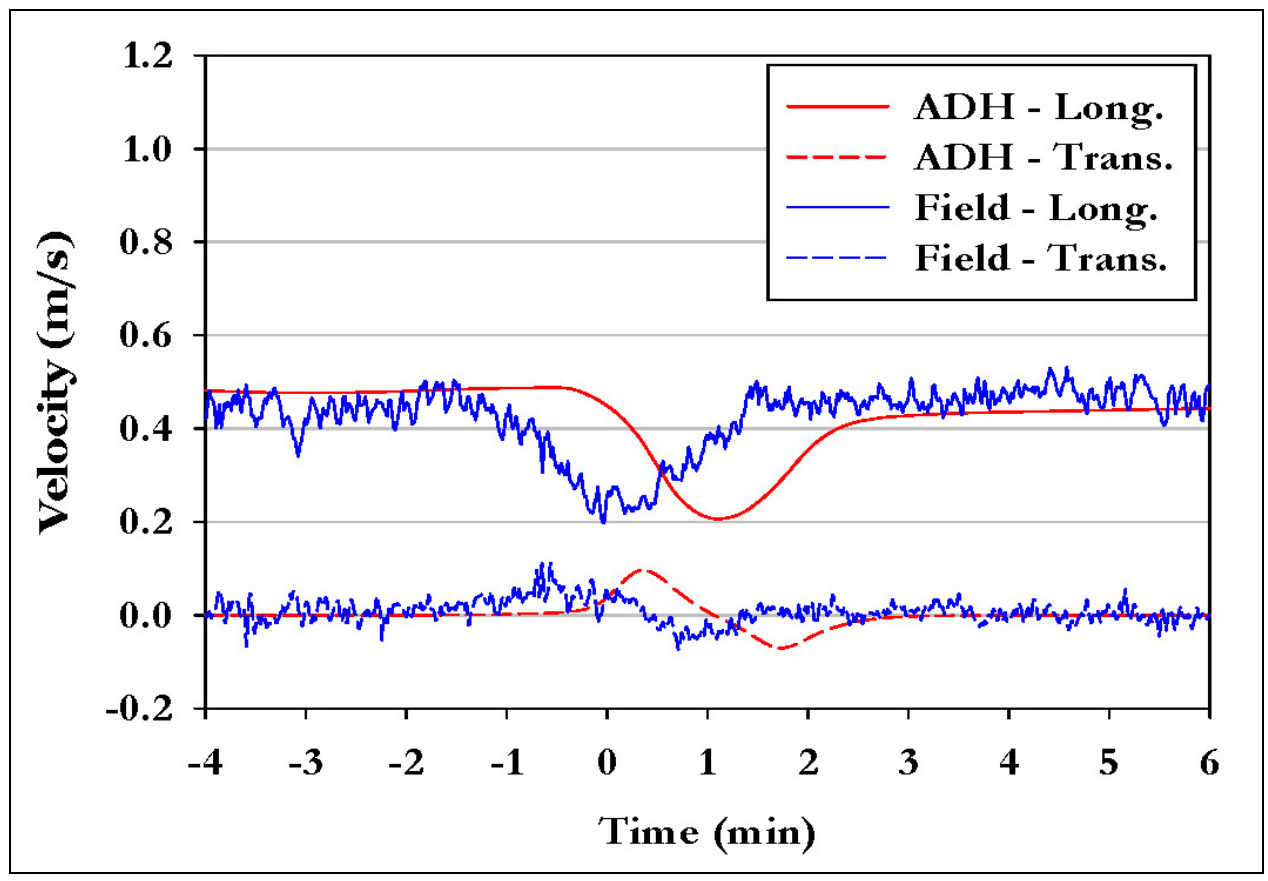

Figure E2. Longitudinal and transverse velocity history, Gauge 071. 


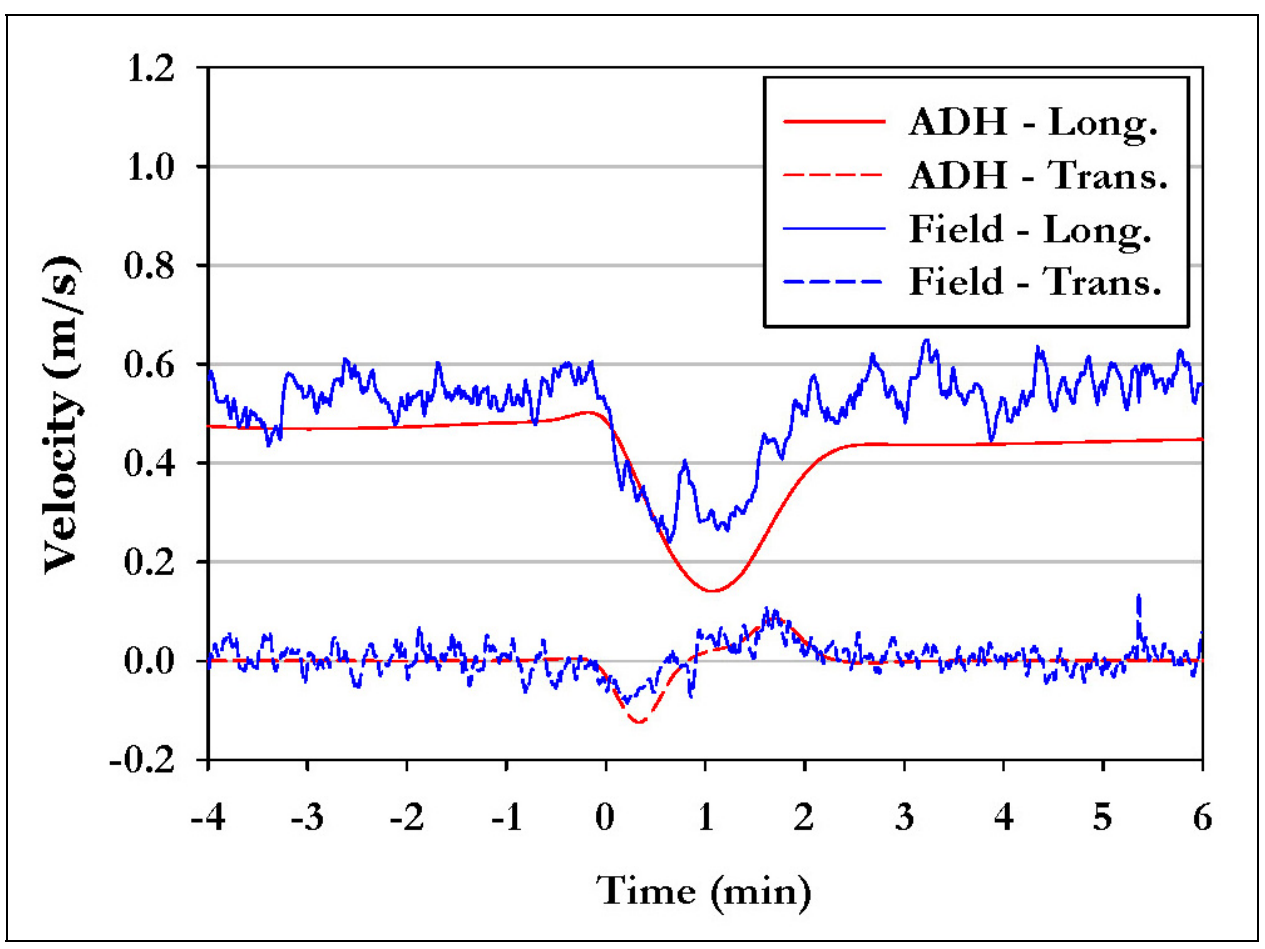

Figure E3. Longitudinal and transverse velocity history, Gauge 332.

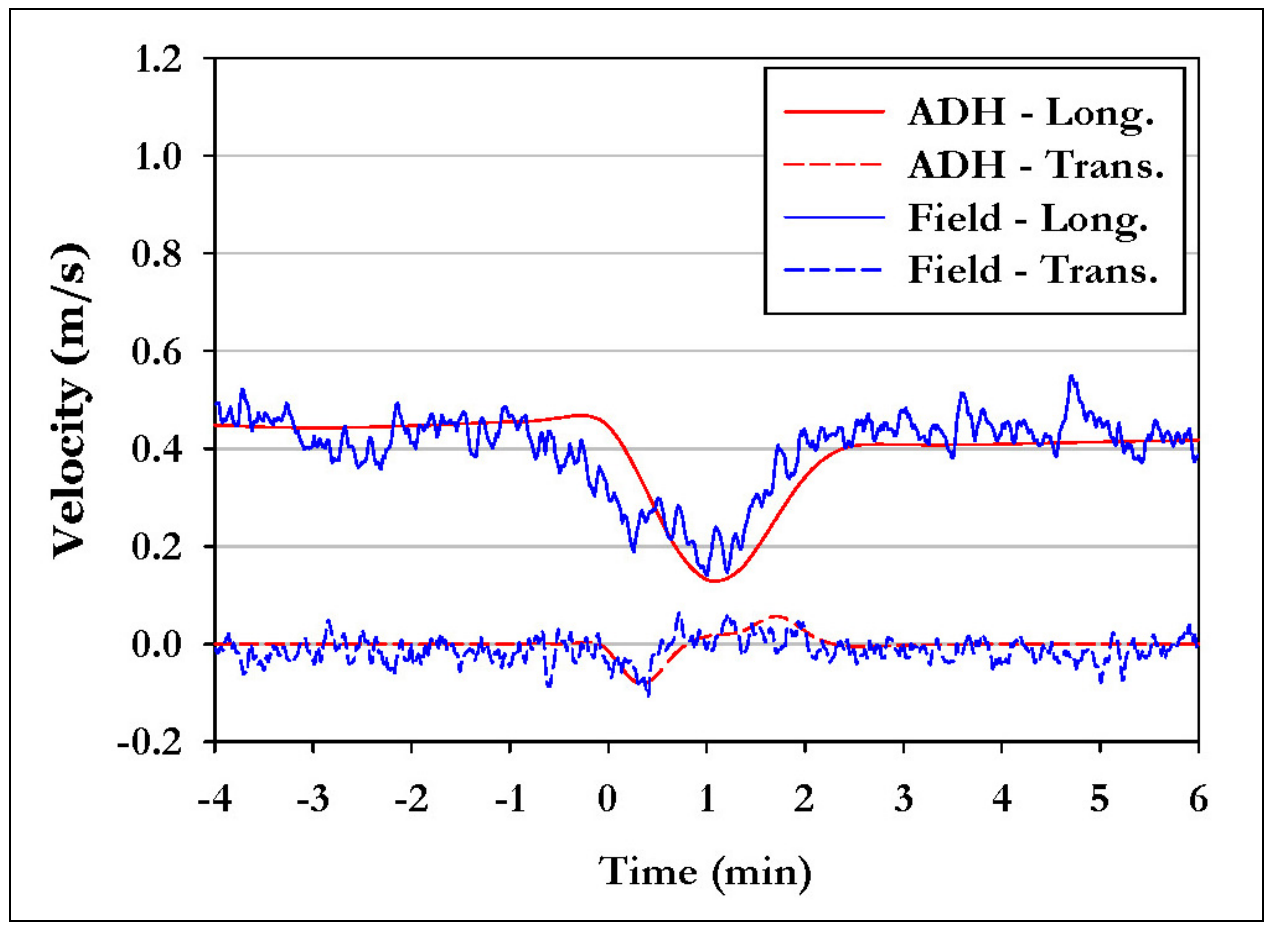

Figure E4. Longitudinal and transverse velocity history, Gauge 642. 


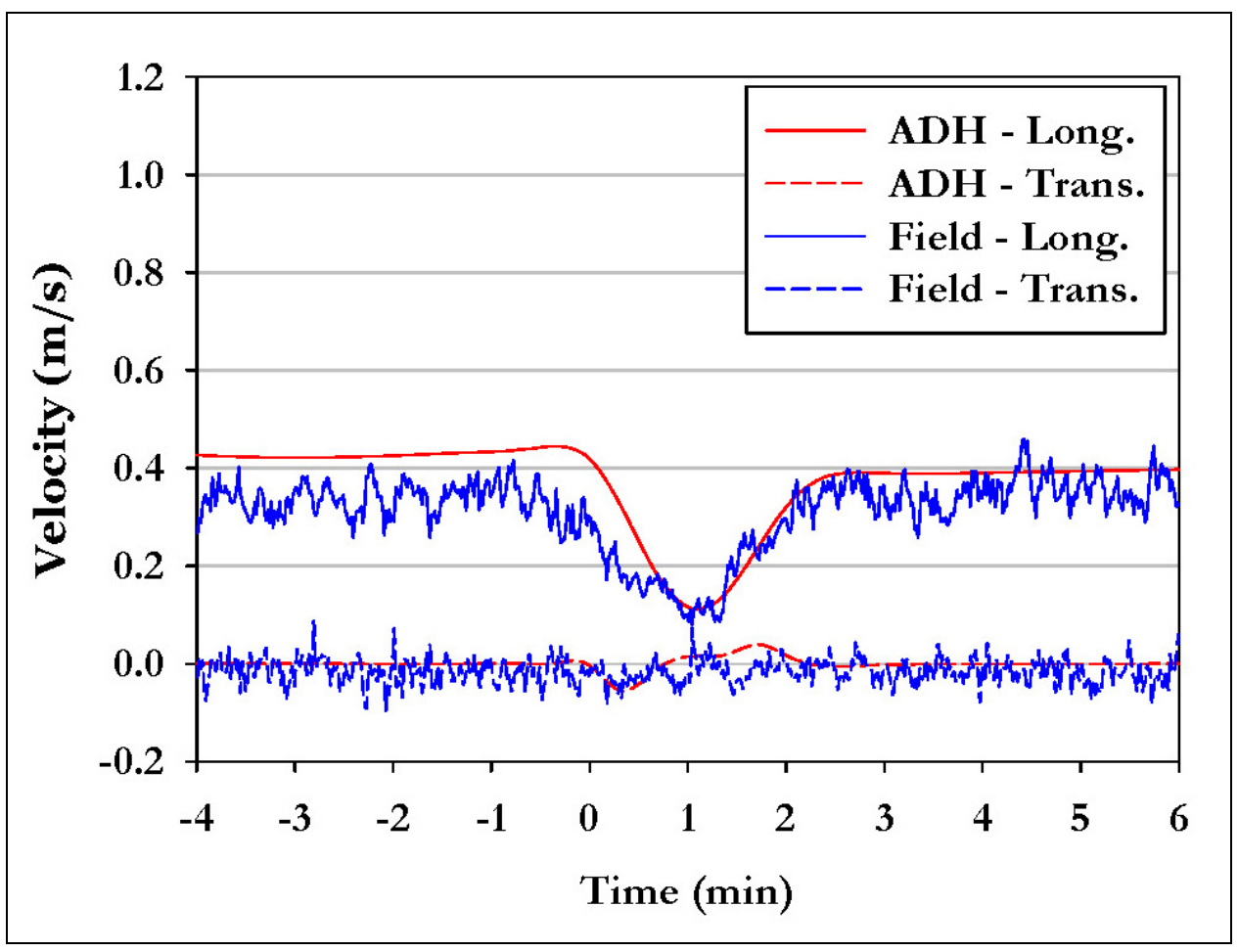

Figure E5. Longitudinal and transverse velocity history, Gauge 999. 


\title{
Appendix F: List of Variables
}

\author{
Variable Definition \\ $A_{1}, A_{2} \quad$ empirical constants \\ $A_{R} \quad$ element aspect ratio \\ $\beta_{\text {wake }} \quad$ propeller-induced bed shear stress decay rate \\ C empirical constant \\ $C_{\text {bow }} \quad$ bow correction coefficient \\ $C_{f s} \quad$ skin friction coefficient \\ D vessel draft \\ $\Delta t \quad$ length of time step \\ $D_{0} \quad$ the jet diameter at the location of maximum contraction of the jet \\ $D_{\text {prop } \quad \text { propeller diameter }}$ \\ E empirical constant related to the nozzle type \\ $f \quad$ constant related to the increase in jet velocity caused by the propeller \\ velocity and geometry \\ $G \quad$ Acceleration due to gravity \\ $H \quad$ flow depth under the vessel \\ $H_{\text {prop }} \quad$ flow depth under the propeller \\ $L_{e} \quad$ element length \\ $P \quad$ pressure head induced by the vessel \\ $P \quad$ pressure underneath the vessel \\ $P_{\text {ves }} \quad$ total vessel power (in hp) \\ $P \quad$ fluid density \\ $T_{\text {prop }} \quad$ thrust per propeller \\ $\tau_{f}$ \\ bed shear stress induced by the flow-field velocity \\ $\tau_{\text {prop }} \quad$ propeller-induced bed shear stress \\ $V_{a} \quad$ flow velocity ahead of the vessel \\ $V_{f} \quad$ flow velocity magnitude (ambient) \\ $V_{g} \quad$ vessel velocity relative to the ground \\ $V_{\text {jet }} \quad$ velocity of the jet produced by the propeller
}




\section{Variable Definition}

$V_{\text {prop }}$

maximum bottom velocity from the propeller relative to the vessel

$V_{\text {shear }}$ velocity used in the calculation of the propeller-induced bed shear stress

$V_{w}$ vessel velocity relative to the ambient flow (in $\mathrm{m} / \mathrm{s}$ )

$V_{\text {wake }}$ wake velocity astern of the vessel

$V_{\text {wake, } \max }$ maximum wake velocity relative to the ambient flow velocity

$W_{e}$ element width 


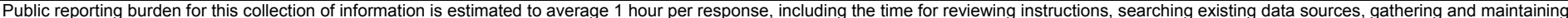

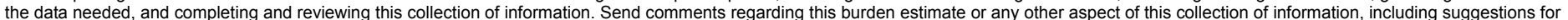

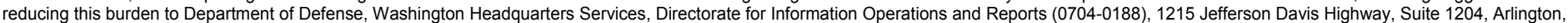

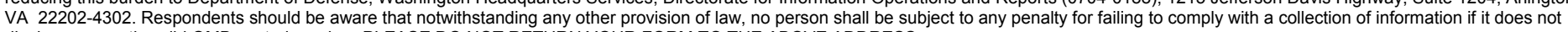
display a currently valid OMB control number. PLEASE DO NOT RETURN YOUR FORM TO THE ABOVE ADDRESS.

\section{REPORT DATE (DD-MM-YYYY) June 2008}

\section{TITLE AND SUBTITLE}

Modeling Vessel-Generated Currents and Bed Shear Stresses

6. AUTHOR(S)

E. Allen Hammack, David S. Smith, and Richard L. Stockstill
3. DATES COVERED (From - To)

5a. CONTRACT NUMBER

5b. GRANT NUMBER

5c. PROGRAM ELEMENT

5d. PROJECT NUMBER

5e. TASK NUMBER

5f. WORK UNIT NUMBER

8. PERFORMING ORGANIZATION REPORT NUMBER

ERDC/CHL TR-08-7

U.S. Army Engineer Research and Development Center

Coastal and Hydraulics Laboratory

3909 Halls Ferry Road

Vicksburg, MS 39180-6199

9. SPONSORING / MONITORING AGENCY NAME(S) AND ADDRESS(ES)

10. SPONSOR/MONITOR'S ACRONYM(S)

Headquarters, U.S. Army Corps of Engineers

Washington, DC 201314-1000

11. SPONSOR/MONITOR'S REPORT NUMBER(S)

\section{DISTRIBUTION / AVAILABILITY STATEMENT}

Approved for public release; distribution is unlimited.

\section{SUPPLEMENTARY NOTES}

\section{ABSTRACT}

Adaptive Hydraulics (ADH) is a computational fluid dynamics package that solves the Navier-Stokes equations and shallow water (depth-averaged Navier-Stokes) equations on two- and three-dimensional computational meshes for overland flow, sediment transport, and groundwater problems. The capability to model the hydrodynamic effects of vessels moving through a two-dimensional flow field has been added to ADH. Using empirical relations developed by Maynord (2000), the bed shear stresses induced by a barge bow and towboat propeller may also be calculated, which, in turn, can be used to predict sediment transport. Guidelines have been developed for sufficient mesh refinement near the vessel and appropriate values for the mesh adaption parameters in ADH. To demonstrate the new modeling capability, this report describes in detail a study of the effects of a vessel sailing through a stretch of the Illinois Waterway near Kampsville, IL. The vessel-induced shear stresses are also reported for the Kampsville study.

\section{SUBJECT TERMS}

Adaptive hydraulics (AIDH)

Sediment transport
Hydrodynamics

Wave modeling

\begin{tabular}{|c|c|c|c|c|}
\hline \multicolumn{3}{|c|}{ 16. SECURITY CLASSIFICATION OF: } & \multirow{2}{*}{$\begin{array}{l}\text { 17. LIMITATION } \\
\text { OF ABSTRACT }\end{array}$} & \multirow{2}{*}{$\begin{array}{l}\text { 18. NUMBER } \\
\text { OF PAGES }\end{array}$} \\
\hline $\begin{array}{l}\text { a. REPORT } \\
\text { UNCLASSIFIED }\end{array}$ & $\begin{array}{l}\text { b. ABSTRACT } \\
\text { UNCLASSIFIED }\end{array}$ & $\begin{array}{l}\text { c. THIS PAGE } \\
\text { UNCLASSIFIED }\end{array}$ & & \\
\hline
\end{tabular}

Illinois River

19a. NAME OF RESPONSIBLE PERSON

19b. TELEPHONE NUMBER (include area code) 